NBER WORKING PAPER SERIES

\title{
MEASURING POVERTY AMONG \\ THE ELDERLY
}

Angus Deaton

Christina Paxson

Working Paper 5296

\section{NATIONAL BUREAU OF ECONOMIC RESEARCH 1050 Massachusetts Avenue \\ Cambridge, MA 02138 \\ October 1995}

This paper was prepared for the NBER Conference on Aging held on May 11-13, 1995. Thanks are due to seminar participants at that conference, our discussant Doug Bernheim, seminar participants at RAND, and to Bo Honore. This research was supported by the National Institute of Aging through grants P01-AG05842 and R01-AG11957. The opinions in this paper do not necessarily reflect the views of the NBER or the sponsoring organization. This paper is part of NBER's research program in Aging.

(C) 1995 by Angus Deaton and Christina Paxson. All rights reserved. Short sections of text, not to exceed two paragraphs, may be quoted without explicit permission provided that full credit, including $\odot$ notice, is given to the source. 


\title{
MEASURING POVERTY AMONG \\ THE ELDERLY
}

\begin{abstract}
Poverty counts are counts of individuals in poverty but are calculated from household or family data on income or expenditure. The transition from one to the other requires assumptions about intrahousehold allocation, about differences in needs across different people, and about the extent of economies of scale. The number of elderly in poverty, or the number of children in poverty, is sensitive to these assumptions and to differences in living arrangements across age groups. We explore the sensitivity of poverty counts to variations in assumptions about child costs and economies of scale using data from the United States and from six large Indian states. Because living arrangements of the elderly are so different in the United States and India, the use of the latter forces us to think about household structure and poverty in the United States. We argue that the official poverty counts in the United States are compromised by unrealistically high costs of children and by unrealistically high economies of scale. We provide a discussion of how economies of scale and child costs can be estimated from the data, using identifying assumptions that label private goods and adult goods, and we make calculations based on the 1990 Consumer Expenditure Survey. We obtain plausible estimates of child costs, together with a number of interesting but hard-to-explain anomalies when we try to estimate economies of scale.
\end{abstract}

Angus Deaton

221 Bendheim Hall

Princeton University

Princeton, NJ 08544-1022

and NBER
Christina Paxson

219 Bendheim Hall

Princeton University

Princeton, NJ 08544-1022

and NBER 


\section{Introduction}

In the United States in 1992, there were four million elderly adults who were officially classified as poor. There were 31 million elderly in the US in 1992, so that the poverty rate was just under 13 percent. Children were much more likely to be poor than the elderly; 22 percent or 15 million children were poor. This paper is about where such numbers come from and what (if anything) they mean. The data used to make the official calculations do not tell us anything about individual poverty. Instead they provide information on the income of families, information that is used to construct a set of poverty counts about individuals. The transformation from families to individuals makes many assumptions, about the allocation of resources within the household, about the differential needs of children, adults, and the elderly, and about the extent of economies of scale. Given the data, the effect of these assumptions on the poverty count depends on living arrangements, on how people combine to form families, on whether people are married or co-habit, on whether the elderly live by themselves or with other, younger adults.

In this paper we examine how living arrangments affect poverty measurement in the context of two countries, the United States and India. The importance of living arrangements is highlighted by comparing the US with a poor country like India. In the US in 1992, 32 percent of those aged 65 or over lived alone, and a further 42 percent lived in all elderly families, so that only 26 percent lived in families with at least one non-elderly person. In our Indian data, 88 percent of the rural elderly and 91 percent of the urban elderly live with one or more younger adults. Conclusions about the living standards of the elderly in India are therefore less determined by the data than by assumptions about who gets what and how poverty lines vary with household composition. Although it is perhaps less obvious in the US, and certainly less attention is paid to it, the same is true. We demonstrate the fact by calculating the sensitivity of poverty counts to key assumptions in their construction, we examine the basis for the assumptions, and we explore whether the empirical evidence has anything useful to contribute.

There are two problems in passing from family resources to individual welfare, one of which is the main topic of this paper. The first issue, on which we shall have little to say, is the intra household allocation of resources. The measurement of individual poverty requires a rule for assigning welfare levels to individuals, based on the consumption or income level of the family or household in which they live. Any rule inevitably contains implicit assumptions about how 
resources are shared between different household members, for example by age or sex. The issue is at its most acute in countries such as India, where the elderly typically live in extended families. When 90 percent of them live with other people, it is impossible to use household survey data to make simple statements about the resources available to elderly people in India. The issue is of less importance in the United States, where a large fraction of the elderly live alone or with other elderly adults.

The second problem is the one to which we give most attention here. Even if resources are distributed equitably across household members, the size and age structure of households affects the welfare levels of their members. The same level of income or income per capita does not give the same standard of living to a large family as to a small one, nor to one an all adult household compared with one with children. Larger households may be able to take advantage of "scale economies" when they share the consumption of public-goods in the household, so that members of large households are likely to be better off than those of small households, even controlling for per capita income or total expenditure. Likewise, if children cost less than adults then households with more children will require lower incomes to achieve a specified standard of living, given total household size. These issues are likely to be of particular importance when comparing poverty rates across age groups, and are also likely to play out differently in countries with different living arrangements for elderly individuals. In the United States, where the elderly typically live in small households with few children, the treatment of child costs is unlikely to have large effects on the numbers of old people in poverty, although it can potentially have large effects on the poverty of the old relative to the young. Even when old people live alone, so that we can measure their resources from a household survey, we cannot classify them as poor or non-poor without a standard of comparison, a standard that cannot be derived without assessing the needs of other non-elderly members of the population. The treatment of scale economies is likely be an important issue for both absolute and relative poverty rates of the elderly. Once again, the comparison with India is instructive given the sharp differences in the living arrangements of the elderly in the two countries. Because the Indian case is so much more extreme than the US, it helps us think about conceptual issues that might not otherwise come into clear focus. 
Our first task is to examine the sensitivity of poverty measures in the US and India to assumptions about child costs and scale economies. We then attempt to estimate the size of scale economies and child costs in the US, for which we have suitable consumption data. We proceed as follows. In the next section, we begin by describing how official poverty measures are derived in the US and India, and we present official poverty counts and rates for members of different age groups. The results for the US are based on data from the 1993 Current Population Survey (CPS), which records information on 1992 incomes. Those for India are based on data from the 1987 National Sample Survey (NSS), and are drawn from Deaton and Paxson (1995). We show that, for each country, poverty measures for different age groups are quite sensitive to the treatment of scale economies and costs of children. In the third section we focus on the measurement of scale economies and child costs. We use data from the 1990 Consumer Expenditure Survey (CEX), a US survey of consumption expenditure. The calculations we do for the United States have not yet been done for India, since the NSS data are not available for use outside of India.

\section{Poverty and age}

Very different methods are used to obtain official estimates of poverty in the US and India. We first provide a brief summary of how official poverty counts are derived in each country. Further information can be obtained from Ruggles (1990) and National Research Council (1995), for the US, and for India from Govermment of India (1993).

In the United States, an individual is said to be poor if he or she lives in a family whose total income falls below a poverty line, where the poverty line depends on the size and age structure of the household. Thus, all individuals within a family are either poor or non-poor: the implicit assumption is that resources are allocated fairly within households, so that all members have identical welfare levels. Official poverty statistics are based on information from the March Current Population Surveys, which are conducted annually and contain information on the demographic characteristics and incomes of households. Income is before-tax and includes cash transfer payments from the government, but does not include nonmonetary transfers such as food stamps, health benefits, or subsidized housing. Several details deserve mention: 
(i) The Current Population Survey has a structure that distinguishes between households and families. Although most households contain only one family, some contain multiple families, and others contain families that live with unrelated individuals. Of the 58,970 households surveyed in the 1993 CPS, 5,763 were not single-family households. For the purposes of measuring poverty, the Bureau of Labor Statistics combines the incomes of families and related subfamilies. For example, a married couple living with a son and daughter-in-law would be treated as a single family: their income would be combined and compared to the poverty line for a 4-person family to determine whether or not all household members are in poverty. However, unrelated subfamilies and individuals are not considered part of the main family, and their poverty measures are based on their own incomes. For example, a person who boards with an unrelated family would be in poverty only if his or her personal income fell below the poverty line for a single person. The poverty line would not adjusted for the fact that such a person, because he or she does not live alone, may benefit from scale economies in consumption.

This definition of families has some odd consequences. For example, unmarried couples who live together are treated as separate families. Each is assigned the poverty line of a single person, and each is defined to be poor if his or her personal income is below the line. This treatment of unmarried couples tends to increase poverty rates over what they would be if unmarried were treated the same as married couples, for two reasons. First, the US poverty lines assume large economies of scale, so that the poverty line for a married couple is less than twice (in fact, only 1.29 times) the line for a single adult. Two unmarried adults who live together and are both in poverty can potentially move themselves out of poverty simply by getting married. Second, even with no scale economies built into poverty lines, treating unmarried couples as if they were married will reduce poverty counts. Combining the incomes of unmarried couples imposes a meanpreserving reduction in the spread of income per person, thus lowering poverty rates. This is exactly the same argument (in reverse) as is in Haddad and Kanbur (1990), who show that poverty measures will be understated if it is assumed that resources are allocated equally across family members when in fact they are not. The fact that official US poverty measures depend on legal marital status is worrisome, especially given the increase in the numbers of co-residing unmarried couples over the past several decades. 
In what follows, we present poverty measures that are based on the official definition of a family, but we also present measures that are based on the total incomes of all members of a household (whether or not the members are related). For these latter computations we use the poverty line that would be applied if all household members were related. Since we are interested in how household scale economies affects living standards, it makes sense to use the household (i.e. individuals living together in the same quarters) rather than the family (i.e. those related by blood or marriage) as the unit of analysis. The switch from a family to a household basis is also one of the recommendations of the National Academy study on the poverty line.

(ii) The United States has used essentially the same set of poverty lines since the 1960 's, adjusting them only for the effects of inflation. The lines depend on the size and age structure of households. They were originally calculated as the cost of the US Department of Agriculture's "low-cost food plan" for households of different sizes and age structures, multiplied by three. The multiplier of three was selected because it was the inverse of the average budget share for food in a 1955 Department of Agriculture survey. Table 2.1 shows a subset of the poverty lines used in 1992 (and applied to the 1993 CPS data which refers to 1992); to save space we have trimmed off poverty lines for families with more than six members and families with more than four children.

Several features of the table are important for our analysis. First, the poverty lines for oneand two-person families depend on whether or not the reference person in the family is elderly. ${ }^{1}$ The implicit assumption embodied in the table is that older people need less money to achieve a given welfare level and the poverty line of an elderly person living alone is $\$ 570$ less than that of a non-elderly person living alone, a "discount" equal to 7.8 percent of the poverty line for the nonelderly person. Note, however, that this adjustment to the poverty line is made only if the reference person is elderly, and families containing elderly who are not the reference person receive no adjustment to their poverty lines. Second, the poverty lines in the table make implicit adjustments for the costs of children and household size. As seems sensible, increases in family size result in

${ }^{1}$ In the CPS the term "reference person" is synonymous with the term "householder". This person is defined in the CPS documentation as "the person (or one of the persons) in whose name the housing unit is owned or rented (maintained) or, if there is no such person, any adult member, excluding roomers, boarders, or paid employees." If a married couple jointly owns or rents a home, either person may be designated as the reference person. 
less-than-proportional increases in the poverty line, holding the number of children constant. Increases in the number of children, holding family size constant, also affect the poverty line, but in neither a simple nor reasonable fashion. For example, the poverty line for a 3-person family with no children is less than that of a 3-person family with one child. In this case the substitution of a child for an adult increases the poverty line by 2.9 percent. The implication is that children cost more than adults, which seems odd given that the poverty lines are based on baskets of food. The poverty lines for families with 4 people are even stranger; the line rises as we go from a 4adult family to a 3-adult 1-child family, falls as we go to a 2-adult 2-child family, and then increases for a 1-adult 3-child family. Overall, the poverty lines in Table 2.1 contain the implicit assumptions that, given family size, old people are relatively cheap and children are relatively expensive. However, the poverty lines also imply economies of scale, so that the high expense of children may be offset by the fact that children tend to live in larger families. These assumptions about costs of children and old people, and scale economies, will affect any conclusions about the poverty of the old relative to the young. We will return to these aspects of the table below, but they are useful to keep in mind when comparing official poverty rates across age groups.

Poverty counts in India are based on a simpler (but not necessarily better) method. A person is said to be in poverty if the per capita consumption level of the person's household is below a poverty line. The poverty lines do not vary across households of different sizes or age structures, although there are different official poverty lines for rural and urban households. The official lines for rural and urban areas were first set in 1979, and have since been adjusted for inflation using an all-India price deflator. They were derived by first specifying different minimum daily calorie levels for people in urban and rural areas, and then using estimates of calorie-expenditure Engel curves (fitted using household data) to find the household per capita expenditure levels that correspond to the minimum caloric levels. The official lines in 1987 were 152.1 rupees per person per month in urban areas, and 131.8 rupees per person per month in rural areas. Recently, an Expert Group commissioned by the Indian government has developed a set of poverty lines that use state-specific price indexes to adjust poverty lines from year-to-year, but like the official lines there is no adjustment to account for possible economies of scale or differences in the costs of children and adults. In what follows we present results using the older set of poverty lines. 
Table 2.2 provides estimates for the US of the numbers and fractions of elderly people, nonelderly adults, and children less than 18 years of age in poverty, using the official poverty lines. The top panel uses family income to measure poverty, and the bottom panel uses household income. Individuals living in "group quarters" were excluded for these and all subsequent calculations. Using official poverty lines, there are 10.9 million more poor children than poor elderly adults. Poverty rates for children are also higher (22.14 percent versus 12.87 percent), and poverty rates for elderly and non-elderly adults are very close. This is true whether we use families or households as the unit of analysis, although as is to be expected, poverty rates using household-level data are slightly lower for all age categories.

Table 2.3 shows poverty rates for elderly and non-elderly individuals (including children) from rural and urban areas of six Indian states (Gujarat, Karnataka, Kerala, Madhya Pradesh, Maharashtra, and Tamil Nadu) which together contain over half of India's population. The data sets on which these calculations are based are large. For nural areas there are 25,992 households containing 146,188 people. For urban areas there are 18,496 households and 89,175 people. We define the elderly to consist of those aged 60 or older, which is the standard definition used in Indian government publications. The fraction of people who are elderly ranges from 5.1 percent to 8.5 percent across states and regions. For all states and regions the poverty rates for the Indian elderly are less than for non-elderly people, and these differences are more pronounced in rural areas. We cannot currently calculate poverty separately for children and non-elderly adults, as we do for the United States.

Given the arbitrariness and controversy surrounding the choice of poverty lines, it is important to examine the extent to which these results are sensitive to how it is set. A useful way to address the question is to graph cumulative distribution functions for income for different groups (children, non-elderly adults and elderly adults), and see if the distribution of living standards of some groups first-order stochastically dominate those of other groups. If the distribution of one group stochastically dominates that of another, then the poverty rate for that group will be lower at any poverty line. A minor hitch is that there is no single poverty line for the US. Rather, we have a set of poverty lines for families of different sizes and composition. To draw the cumulative distributions we must first "re-base" family income to make it comparable across families with different 
sizes and numbers of children. Specifically, we choose families with 2 adults and 2 children as the "base," with a poverty line of $\$ 14,228$ from Table 2.1. The living standard of person $i$ in family $f$ is then measured as :

$$
y_{i f}^{*}=y_{f}\left(z_{b} / z_{i}\right)
$$

where $y_{f}$ is the income of family $f, z_{f}$ is its poverty line, and $z_{b}$ is the poverty line of the base family. We then graph cumulative distribution functions for $y_{i}^{*}$ for children, non-elderly and elderly adults.

The results of this exercise (which use the family rather than the household as the unit of analysis) are shown in Figure 2.1. The left panel graphs the cumulative distributions for the three groups. Since we are interested in whether the poverty counts are sensitive to choice of poverty line, we graph the distribution functions only up to $\$ 20,000$, and so any conclusions about stochastic dominance are restricted to this range of income. The "base" poverty line of $\$ 14,228$ is shown as a point of reference. The right panel of the figure graphs two lines: the vertical difference between the cumulative distributions for elderly and non-elderly adults, and the vertical difference between the distribution for children and non-elderly adults. The Figure shows that the living standards of adults first-order stochastically dominate those of children. The distribution functions for the elderly and non-elderly adults cross at an income level slightly below the poverty level, indicating that at lower poverty lines the elderly would be less poor than the non-elderly. This may reflect the fact that social security provides an income floor for most elderly citizens.

Figure 2.2 shows the corresponding graph for the rural region of one Indian state, Gujarat. Since in India there is a single poverty line expressed in terms of monthly per capita expenditure, there is no need to "re-base" the measures of living standards as was done for the US. Two poverty lines are shown: the official line of 131.8 rupees, and the new line of 115 rupees recommended for rural Gujarat by the Expert Group. The results for Gujarat are similar to those of other Indian states and regions (see Deaton and Paxson, 1995). The distribution of living standards of the elderly stochastically dominates that of the non-elderly at all reasonable poverty lines.

The key question is how sensitive these results are to different treatment of child costs and scale economies implicit in the US and Indian methods of setting poverty lines. A straightforward 
exercise for the US is to examine how the numbers change if the old-age "discount" to poverty line is removed, so that one- and two-person families with an elderly reference person receive the same poverty line as do those with younger reference people. The results of these tabulations are shown in Table 2.4. When the unit of analysis is the family, the number of elderly in poverty increases by 716 thousand people, from 4 to 4.7 million people, and the rate of poverty among the elderly increases from 12.87 percent to 15.19 percent. There are only tiny increases in poverty among other groups, reflecting the fact that the old-age discount applies to only one and two person families with an elderly reference person, and that most elderly people in 2 person families live with other elderly people.

The poverty lines in Table 2.1 contain strong implicit assumptions about the costs of children and economies of scale, and it is useful to examine how poverty rates for different age groups changes as the assumptions are modified. However, making ad hoc adjustments to the table of poverty lines does not seem especially desirable. The approach we take is to specify the poverty line as a function of the age and size composition of the family, and fit this function to the official poverty lines. We can then examine how sensitive poverty measures are to child costs and scale economies by altering the parameters of the function. Specifically, we specify the poverty line for family with $A$ adults and $K$ children as:

$$
z(A, K)=z_{b}(A+\alpha K)^{\theta},
$$

where the term $(A+\alpha K)^{\theta}$ represents the number of "adult equivalents" in the household, and $z_{b}$ is the per capita poverty line for a base household. In what follows we refer to the term $(A+\alpha K)$ as the "effective household size." The parameter $\alpha$ measures the cost of children relative to adults, and the parameter $\theta$ reflects economies of scale. For example, a value of $\theta$ equal to 0.5 implies that doubling effective household $\operatorname{size}(A+\alpha K)$ multiplies the poverty line by the square root of two, or 1.41 .

We take logarithms of (2.1) and fit the resulting equation to the actual data on poverty lines, numbers of adults and numbers of children. Using the complete list of poverty lines, we obtain estimates of $\alpha$ equal to 1.3 and $\theta$ equal to 0.47 . The high value of $\alpha$ reflects the fact that for smaller families the actual poverty lines increase as the numbers of children increase, and that the majority of families in our sample are small: 77.7 percent of families have fewer than 4 members, 
and less than nine percent have more than 4 members. When we establish a baseline by recomputing age-specific poverty rates using the poverty lines estimated using (2.1), with $\alpha$ equal to 1.3 and $\theta$ equal to .47 , we obtain estimates very similar to those using the actual poverty lines: the poverty rate among children is 22.0 percent, among non-elderly adults is 11.5 percent, and among elderly adults is 14.4 percent. That the poverty rate among elderly adults is somewhat higher than the "official" rate of 11.65 percent in Table 2.2 is not surprising, given that we have not built an old-age discount into our estimated poverty lines.

We are now in a position to examine how changes in the costs of children, as measured by $\alpha$, and changes in scale economies, as measured by $\theta$, affect the poverty of the old relative to other age groups. We present these results graphically, by showing cumulative distributions of living standards for people in different age groups, where living standards are measured as:

$$
y_{i f}^{*}=y_{f} \frac{z(2,2)}{z\left(A_{f}, K_{f}\right)}=y_{f} \frac{(2+\alpha 2)^{\theta}}{\left(A_{f}+\alpha K_{f}\right)^{\theta}}
$$

so that as before our "base" family has two adults and two children, so that for families of this type living standards are simply measured as family income.

Before proceeding, it is useful to think about how we might expect changes in $\alpha$ and $\theta$ to affect the living standards of individuals relative to those in base households. Taking derivatives of the logarithm of equation (2.2) with respect to $\alpha$ yields:

$$
\frac{\partial \ln y_{i f}^{*}}{\partial \alpha}=\theta\left[\frac{2}{2+\alpha 2}-\frac{K_{f}}{A_{f}+\alpha K_{f}}\right],
$$

which is positive for households with smaller ratios of children to effective household size than

$$
\frac{\partial \ln y_{i f}^{*}}{\partial \theta}=\ln \left[\frac{2+\alpha 2}{A_{f}+\alpha K_{f}}\right]
$$

the base household, and negative for others. Increases in the cost of children raise the relative living standards of households with small fractions of members who are children, and reduce the relative living standards of those with large fractions. The derivative with respect to $\theta$ is: 
which implies that increases in the scale parameter $\theta$ will raise the relative living standards of those in families with small numbers of effective members, and lower the relative living standards of those in large families. Thus, the living arrangements of the elderly-the size of their families as well as the ratios of children to household size-will determine the effects that changes in child costs and scale economies have on living standards.

Tables $2.5 \mathrm{a}$ and $2.5 \mathrm{~b}$ present evidence on the family sizes and fractions of members who are children for people of different ages, for the US and India. In the US, the elderly live in households that are on average smaller than those of children and non-elderly adults. The average household size for an elderly person is 1.94 , as opposed to 3.04 for a non-elderly adult and 4.38 for a child. In consequence, poverty measures that assume greater household scale economies will increase the poverty of the old relative to the young, with the primary beneficiaries of scale economies being children. Likewise, the average ratio of children to family size for elderly people is only 0.013 , far lower than the average ratios of 0.203 for younger adults, and 0.533 for children. Poverty measures that assume smaller costs of children will also increase the poverty of the elderly relative to children, and also increase their poverty relative to the younger adults with whom children reside.

The Indian situation is somewhat different. As in the US, Indian elderly live in households with smaller fractions of children, so that, once again, reducing child costs will increase the relative poverty of the old. However, the differences in the age composition of households across the elderly and non-elderly are not nearly as pronounced as they are in the United States. Elderly live in households in which children comprise over 20 percent of members on average, whereas this fraction is between 34 percent and 39 percent for non-elderly people. In addition, the Indian elderly do not live in households that are substantially smaller than those of the non-elderly. In rural areas the average household size for elderly people is only 0.53 people less than for non-elderly people. In urban areas this difference is even smaller, only 0.08 . In this situation, different assumptions about scale economies are likely to have little effect on relative poverty measures.

Figure 2.3 shows the results of altering $\alpha$ and $\theta$ on the cumulative distributions of family income in the United States. The top left graph shows the distributions with $\alpha$ equal to 1.3 and $\theta$ equal to 0.47 , the values obtained using the official poverty lines. Consistent with Figure 2.1, the 
distribution of living standards for children is stochastically dominated by that of elderly and nonelderly adults, and the lines for elderly and non-elderly cross near the official poverty line for the base family. As one moves from the top left graph to the top right graph, $\alpha$ is decreased, from 1.3 to 1.0 to 0.7 . As expected, increases in child costs make the elderly less well-off relative to children, and at an $\alpha$ of 0.7 the cumulative distributions for the elderly and for children cross at an income level only slightly above the official poverty line. The three graphs in the bottom panel also let $\alpha$ vary from 1.3 to 0.7 , but use a scale parameter $\theta$ equal to 0.75 instead of 0.47 . Scale economies are less important at higher values of the scale parameter, and as expected the elderly become better-off relative to others due to their smaller average family sizes. The information in Figure 2.3 is summarized in Figure 2.4, which shows the differences in the cumulative distributions similar to those shown in Figure 2.1.

The effects of changes in $\alpha$ and $\theta$ can also be seen in Table 2.6, which shows the fraction of individuals with values of $y_{i f}^{*}$ less than the base poverty line of $\$ 14,228$. Holding $\theta$ fixed at 0.47 , the poverty rate of the elderly increases from 14.40 to 19.60 and the poverty rate of children declines from 22.02 to 21.61 as the cost of children declines from 1.3 to 0.7 . It may seem counterintuitive that when child costs are lowered, the poverty rates of children fall very little and the poverty rates of the elderly rise substantially. It should be kept in mind, however, that we have used a 2-adult 2-child family as the base, and that the incomes of base families are unaltered by changes in $\alpha$ and $\theta$. Since a large fraction of children live in 2-adult 2-child families, we are effectively guaranteeing that their poverty rates change little as $\alpha$ is increased. The more general point is that the choice of base family has large effects on the measured levels of poverty. This is illustrated by the right-hand panel of Table 2.6, which repeats the same exercise using a 1 -adult 0 child base. In this case increases in $\alpha$ reduce poverty rates for all age groups, since there are people in all age groups who live with children, but reduces the poverty rate for children the most.

Table 2.6 also shows that the effects of changes in scale economies on relative poverty rates. In general, increases in $\theta$ from .47 to .75 (holding $\alpha$ fixed) increase the poverty of children relative to elderly adults. This is to be expected, given that children live in families that are on average larger than those of other age groups. Again, however, the effect of changes in the scale parameter on absolute poverty rates depends on the definition of the "base family." When the base 
is a 2-adult-2-child family, the poverty rate of children barely changes, while adult poverty rates decline. Using a 1-adult base, increases in the scale parameter result in large poverty increases for all groups, with the largest increase for children.

It is also useful to compare changes in poverty rates as one moves from the case in which both child costs and scale economies are high (i.e. $\alpha=1.3$ and $\theta=.47$ ) to a possibly more realistic case of lower child costs and scale economies (i.e. $\alpha=.70$ and $\theta=.75$ ). These changes in $\alpha$ and $\theta$ have offsetting effects, since large families tend to have more children. Using a 2-adult 2-child base, the poverty rates of children and non-elderly adults are largely unchanged, and that of the elderly declines by less than 4 points. Thus, it is possible that modifying the official poverty lines so that they imply lower child costs and lower scale economies will leave aggregate poverty rates for different age groups largely unchanged. This does not imply, however, that the same people will be in poverty under the two scenarios.

Figures 2.5 and 2.6 show the effects of changes in $\alpha$ and $\theta$ for rural regions of two Indian states, Gujarat and Maharashtra. A set of figures for rural and urban areas of 6 Indian states are in Deaton and Paxson (1995). These figures indicate that, as in the US, reductions in child costs have large effects on the poverty of the elderly relative to the non-elderly populations. In rural Gujarat, the poverty rates of the elderly and non-elderly are nearly equalized if children cost $40 \%$ of adults. In rural Maharashtra, the poverty rates are equalized at a higher child cost of $70 \%$. Unlike in the US, changes in scale economies have little effect on the differences in distributions across age groups. This is to be expected, given the result in Table $2.5 \mathrm{~b}$ that elderly and nonelderly people live in households with similar numbers of household members on average. Economies of scale are of even less importance in urban areas, where differences in household sizes are even smaller.

The conclusion of this section is that the age distribution of poverty is extremely sensitive to the treatment of child costs and economies of scale. In the United States, official estimates of the numbers and percentages of people in different age groups in poverty hinge on poverty lines that contain strong implicit assumptions about child costs and scale economies. The "per capita" poverty lines used in India also contain equally strong implicit assumptions about child costs and scale economies, namely that children cost the same as adults and that scale economies do not 
exist. In both countries, deviations from the assumptions implicit in official poverty lines result in very different poverty measures for different age groups.

In the next section, we examine the empirical evidence on household consumption patterns in a (not very successful) attempt to establish a less arbitrary basis for the costs of children and household economies of scale. As we shall see, there are good reasons to be skeptical of the results. Nevertheless, to the extent that there are results, they are consistent with a value of $\alpha$ around 0.75 and a value of $\theta$ of 0.85 or even higher. Such figures generate poverty counts close to those shown in the last column of Table 2.6 , with $\alpha=.70$ and $\theta=.75$.

\section{Calculating equivalence scales}

\subsection{Introduction}

The official poverty lines in the US differ for different family sizes as shown in Table 2.1. These differentials come from differences in food purchasing patterns in the 1955 survey that Mollie Orshansky used to construct the original poverty line. In consequence, the equivalence scales implicit in the Table have some basis in behavior, although, as we have seen, the pattern of child costs and economies of scale are not easy to defend. Several alternatives to the Orshansky scales have been proposed from time to time. For example, Ruggles (1990) suggests that the scale be proportional to the square root of household size, so that two adults are equivalent to 1.41 single adults, three to 1.73 single adults, and so on. As discussed in Section 2, this rule approximates the Orshansky scale while removing some of its stranger features. Larger families are also typically those with larger numbers of children, and the square root rule should be seen as reflecting not only economies of scale, but also that children cost less than adults. It is also possible explicitly to separate adults and children, and the recent report on the poverty line by the National Academy, NRC (1995), recommends that scales be calculated according to the formula used above, namely $(A+\alpha K)^{\theta}$ for $A$ adults and $K$ children, and recommend values around 0.75 for both $\alpha$ and $\theta$. Alternatively, the OECD (1982) has suggested a scale in which the first adult counts as unity, other adults as $\mathbf{0 . 7}$, and children as 0.5 , so that the economies of scale are not allowed for explicitly, but are reflected in the discount for additional adults and a relatively low cost of children. 
In this section, we use data from the Consumer Expenditure Survey (CEX) in 1990 to try to tease out information about the relative costs of children and adults, and about the extent of economies of scale. That these data should be relevant for such an exercise seems obvious. The CEX collects information on purchases of goods that are differentially consumed by adults and by children, and can be used to infer how these purchases change with the composition of the family. Economies of scale presumably arise because some goods are public and can be shared by several members of the household and an expenditure survey can tell us how the balance between private and public goods shifts with household size and composition. Even so, attempts to infer equivalence scales from budget data have a long and discouraging history. Although expenditure data are relevant to the construction of scales, they are insufficient by themselves to identify them. Additional identifying assumptions are required, and it has been difficult to find such assumptions that are widely acceptable. Worse still, many of the estimates in the literature have been derived under identifying assumptions that are not made explicit, so that it is difficult or impossible to know what the results mean.

We devote the next subsection to the theoretical issues, to the identification issue and what it does and does not imply, and to the basis for our calculations of child costs and economies of scale. The former rests on familiar ground, and calculates the costs of children by comparing the behavior of expenditure on adult goods across households with different numbers of children. The latter uses a new method, suggested to one of us by Jean Drèze, that uses expenditures on private goods to identify the economies of scale to household size that operate through public goods.

\subsection{Identifying equivalence scales}

We begin by explaining what cannot be done, and the consequences of trying. The theory of equivalence scales parallels that of cost of living index numbers and both begin from a description of household preferences in terms of the cost or expenditure function. If total household expenditure is $x$, and if this is efficiently spent to maximize the collective utility of a family of $A$ adults and $K$ children, say, then we can write 


$$
c(u, p, A, K)=x
$$

where $u$ is the collective utility level. By analogy with cost of living numbers, the number of single adult equivalents in a family with $A$ adults and $K$ children is, see Deaton and Muellbauer (1980, 205)

$$
E(A, K ; u, p)=\frac{c(u, p, A, K)}{c(u, p, 1,0)}
$$

an expression that, in general, will depend on prices and on the level of real income of the family. Since the cost function provides a convenient summary of the family's preferences, and since once specified, it can be used to yield a set of demand functions, there is an apparently straightforward way of calculating the equivalence scale in (3.2). Write down some suitable cost function (3.1), for example a translog or almost ideal system, recover the parameters by estimating the associated demand functions, and fill in (3.2). This is what is done, for example, by Slesnick (1993), in his recalculation of poverty in the US.

Pollak and Wales (1979) have shown that such calculations of equivalence scales ignore the central identification problem that the data do not identify the equivalence scales. In particular, Pollak and Wales point out that all cost functions of the form

$$
c(\phi(u, A, K), p, A, K)
$$

have the same demand functions irrespective of the function $\phi$ provided only that it is monotone increasing in $u$. Relabelling indifference curves in a way that depends on family structure has no effect on demand functions, although it clearly changes how we should measure welfare. As a result, the data do not allow us to calculate equivalence scales without additional assumptions that pin down the function $\phi$.

At first blush, it is tempting to associate the identification issue with the fact that parents get utility from children, and to try to separate 'economic' welfare as represented from the structure of the cost function from the 'psychic' welfare that is captured by the function $\phi$. But this hope is not only imprecise, it is wrong, as the following example shows. Consider families that contain only adults, and suppose that we model economies of scale by writing 


$$
c(u, p, A)=A^{\theta} c(u, p, 1) .
$$

so that for $\theta \leq 1$ there are economies of scale, and we want to estimate $\theta$. To fix ideas, suppose that the cost function for the single adult household takes the "quasi-homothetic" form in which costs are a linear function of utility:

$$
c(u, p, A)=A^{\theta} c(u, p, 1)=A^{\theta} a(p)+A^{\theta} b(p) u
$$

where $a(p)$ and $b(p)$ are linearly homogeneous functions of the vector of prices $p$. The demand functions are derived from (3.5) in the usual way; the budget shares take the form

$$
w_{i}=\frac{p_{i} q_{i}}{x}=\alpha_{i}(p) \frac{a(p) A^{\theta}}{x}+\beta_{i}(p)\left(1-\frac{a(p) A^{\theta}}{x}\right)
$$

where $\alpha_{i}(p)$ and $\beta_{i}(p)$ are the elasticities with respect to the ith price of $a(p)$ and $b(p)$ respectively. (That the budget shares for a family of $A$ adults with outlay $x$ are the same as the budget shares for a family with one adult and outlay $x / A^{\theta}$ is a general feature of cost functions of the multiplicative form (3.4)). According to (3.5) and (3.6), preferences and the associated behavior are each weighted averages of preferences at subsistence $a(p)$, with associated budget shares $\alpha_{i}(p)$ and preferences at bliss $b(p)$ with associated budget shares $\beta_{i}(p)$. Given specifications for $a(p)$ and $b(p)$, the demand functions (3.6) can be taken to the data, and $\theta$ estimated together with the other parameters; see for example Lanjouw and Ravallion's (1993) work for Pakistan where the parameter $\theta$ is estimated to be around 0.6 .

Economies of scale in (3.4) operate multiplicatively through the cost function, so that in (3.5) costs at subsistence and costs at bliss are subject to the same economies. But because of fixed costs or other effects, the economies of scale might be more or less effective at higher levels of living. One way of generalizing (3.5) to allow this would be to write

$$
c(u, p, A)=A^{\theta} a(p)+A^{\psi} b(p) u
$$


where $\theta$ and $\psi$ are not necessarily equal. If we now derive the demand functions from these new preferences, either elementary calculation or application of the Pollak and Wales (1979) theorem, we once again retrieve (3.6). Hence, as far as their empirical implications are concerned, (3.5) and (3.6) are indistinguishable. As a corollary, if we take (3.6) to the data and obtain an estimate of $\theta$, it has no particular claim on our attention as a measure of the extent of economies of scale. The scales used in Slesnick's (1993) reworking of the poverty count are obtained by a generalization of the technique outlined above, and are subject to the same criticism. Slesnick's and Lanjouw and Ravallion's estimates are identified by assuming that the particular cardinalization of utility that they chose is correct, rather than the infinite number of other cardinalizations that are indistinguishable on the data, but which would give different results for the scales. Indeed, since Slesnick's results are perhaps even more bizarre than those in the official scales, it is comforting to know that they can be arbitrarily 'corrected' without consequences for the empirical evidence from which they were obtained.

By itself, the empirical evidence on expenditure patterns cannot generate equivalence scales. Instead, we need additional assumptions, typically in the form of prior information that links welfare to behavior. It is to these we now turn.

\subsection{Alternative identification schemes for child costs and economies of scale}

The most famous and venerable of the schemes for linking behavior and welfare is Engel's supposition that families with the same share of food in their budget are equally well off, irrespective of their size and composition. The food share assumption serves as an all purpose scale identifier, allowing us to measure both child costs and economies of scale. For the former, we start from a two adult family (say) and calculate, for any given level of outlay the additional amount that would be required to bring a two adult and one child family to the same food share, which by assumption would be at the same level of welfare. We can equally well equate food shares for a large and a small family so as to calculate the relative outlays that make them equally well off and so estimate any economies of scale. If the cost function is multiplicatively separable in family characteristics on the one hand and prices and utility on the other-as is (3.4)-the food 
share - or any other budget share-does indeed indicate welfare, so that the method is consistent with a well-defined theoretical structure. Furthermore, the assumption that the food share indicates welfare solves the identification impasse; for example, it is easy to check that the food share indicates welfare if the cost function is (3.5), but not when the cost function is (3.7). The Engel assumption ties down the function $\phi$ in (3.3).

Engel's assumption is the kind of assumption that we need, but it is not the right one. As first argued by Nicholson (1976) and elaborated by Deaton and Muellbauer (1986), Engel's assumption is quite implausible. The addition of a child with full compensation would normally increase the food share, not leave it unchanged, in which case the Engel compensation is too large. A better procedure for measuring child costs uses expenditures on adult goods as an indicator of adult welfare, and calculates the compensation that would be required after the addition of the child in order to restore adult expenditures to their previous level. This method was first proposed by Rothbarth (1943) and has been used in the US by Betson (1990) and (more or less) by Lazear and Michael (1988). The Rothbarth procedure is not without its problems. In particular, it takes no account of possible substitution toward adult goods in the presence of additional children, nor of broader rearrangements of consumption patterns that might follow the addition of a child. There is also a shortage of well-measured adult goods in the data. The procedure inevitably uses expenditures on adult clothing and footwear, alcohol, and tobacco, and the last two are much underestimated in the CEX-as in other expenditure surveys around the world-see Geisman (1981). Even so, the Engel method is clearly wrong, and the transparency of Rothbarth's method and its identification assumptions are in sharp and favorable contrast with the mechanical estimation of equivalence scales from demand systems augmented by demographic variables. We present some results using Rothbarth's method below.

The calculation of economies of scale has a less well trodden history. Although the Engel method provides estimates of scale economies, there is no reason to credit them without some theory of why, in the presence of public goods, the food share should correctly indicate welfare between families with different numbers of people. Indeed, there are good reasons for supposing that the Engel method will give the wrong answer. The argument follows much the same lines as 
Nicholson's argument about Engel's method for calculating child costs, and we shall adopt a solution that is similar to the Rothbarth method in that case.

Suppose that there exists a pure private good that is not substitutable for public goods, food being the obvious example. Consider what happens when family size increases, for example by combining two single adults into a family of two adults. Suppose too that compensation is paid, presumably negative compensation since the scale economies in the public good will make the family better off if the two original incomes are simply combined. Because less of the public good is needed than in the two separate single person families, and because there is no substitution from the private to the public good, the budget share of the private good will increase. But according to Engel, a family with a higher food share must be worse off, and less money should be taken away. In consequence, Engel's method will overstate the amount of money needed for the larger household, and thus understate the extent of and discount from the economies of scale.

In our own empirical work in this paper, we adopt an approach to economies of scale that parallels Rothbarth's procedure for measuring child costs. We measure child costs by examining adult goods, and we measure economies of scale by examining the behavior of private goods as household size changes. Consider again the example of the previous paragraph in which two people, previously in single person families, come together to form a two person family. As before, they no longer need as much heat and light, kitchens, bathrooms, and (possibly) bedrooms so that they have more for the private goods, whose share of the budget can be expected to increase. If nothing else happens, we could calculate the extent of the economies of scale, not by restoring the share of private goods to its previous value, but by calculating the reduction in total income that would restore the previous per capita consumption of the private good. If the reduction is (say) twenty percent of total outlay, we have established that there is a twenty percent discount for two people over one. The major caveat is that public goods are effectively cheaper in larger households; an oriental rug or a painting costs the same but provides pleasure to twice as many people. In consequence, there will be substitution away from the private toward the public goods, so that a fully compensated two person family will have lower per capita consumption of private goods than will the two single person families combined. As a result, the reduction in income that restores the per capita consumption of the private good is less than the utility preserv- 
ing reduction, and so understates the extent of economies of scale. This effect will be small if the private good is not substitutable for the public good, as for example food for housing, or we can calculate the income reduction for a range of private goods, and select the one that gives the largest reduction. Although both this method and the Engel (food share) method will understate economies of scale, the latter will do so even in the absence of substitution between private and public goods and will therefore understate by more.

Alternative methods and estimates of economies of scale have been provided by Nelson (1988) and in the National Academy Report. The latter starts from the estimates of child costs obtained by the Rothbarth procedure in Betson (1990), who made separate calculations according to the number of adults in the family. His results can therefore be used to give the costs of an additional child relative to an adult in one adult families, in two adult families, and so on. If it is supposed that the number of equivalent adults is approximated by the formula $(A+\alpha K)^{\theta}$, with parameters the same for different household types, then the differences in child costs across different family types reflects economies of scale and can be used to measure them. In particular, in a family with $A$ adults and $K$ children, the cost of an additional child relative to an adult is given by the formula $[(A+\alpha(K+1)) /(A+\alpha K)]^{\theta}$, which can be fitted to Betson's results to obtain estimates of $\alpha$ and $\theta$. The calculations in the report suggest values of around three-quarters for both $\alpha$ and $\theta$. Unlike the Engel procedure, the Betson and Michael's method appears to be soundly based, at least if we accept the Rothbarth method of estimating child costs. Even so, it can provide only a summary of the scale economies, and yields no insight into the process by which public goods work within the household. Nor does it ensure that economies of scale are what we are measuring, rather than (for example) the possibility that larger households devote less to additional children for some other reason.

Nelson assumes that different goods exhibit different economies of scale, and uses CEX data on all adult families to estimate a demand system that, following Barten (1964), allows explicitly for the patterns of substitution that come from the changes in effective relative prices that are induced by the differential economies of scale. Although the identification of welfare is left implicit, Nelson's procedures are theoretically consistent with the method adopted below. Her model assumes that economies of scale work so that the fractions of family consumption of each 
good received by each person can add up to a total different from unity, and that the sum of these fractions is different for different goods, being larger than unity for goods with economies of scale. Because she makes no allowance for fixed costs, economies of scale can only operate this way, and must result in substitution effects in line with the price effects that the scaling factors are designed to mimic. She works with five broad groups of goods, and finds that all display economies of scale; for housing there are implausibly large economies, with each member of a two person household receiving twice as much in housing services as would each in a one person household. Nelson attributes the result to the fact that, in her data, two person households spend almost the same on housing as one person households, in spite of having incomes that are fifty percent higher. It is also possible that the Barten model should bear some of the blame; high economies of scale act so as to diminish needs and thus consumption, but they also cause an offsetting substitution effect toward the good. When this price effect is substantial, and the data show that two people spend much the same on housing as one person, the model responds by choosing a very large value for the economies of scale. But it is also possible that the model is incorrect, and that economies of scale operate differently, as would be the case if there are fixed costs.

\subsection{Using adult goods to estimate child costs}

We used data from the 1990 Consumer Expenditure Survey (CEX) to examine the behavior of expenditure on adult goods over families with differing numbers of children. Expenditure on adult goods is defined, as is usual, as the sum of expenditures on alcohol, tobacco and adult clothing and footwear. The $1990 \mathrm{CEX}$ has 20,517 observations in total, and we use all of these in the analysis. The CEX is a rolling panel, in which each household is (in theory) interviewed five times at three month intervals, and asked about consumption in the previous three months. New households are added in as other households exit the survey. Because each interview generates an observation, there are only 10,127 different households in the sample. Of these, 3,893 are interviewed once, 3,053 twice, 2,206 three times, and 975 four times. The lower numbers of households with 3 and 4 observations is accounted for my the fact that some households miss inter- 
views and/or drop out of the survey before completing all 5 interviews: 953 of our households do not complete the full series of interviews or have "gaps" between interviews.

We define total expenditure as the sum of expenditures on food, both away and at home, alcohol, tobacco, clothing, housing, transportation excluding purchases of new cars, entertainment, personal care, medical expenditures, reading materials, and educational expenditures. The Bureau of Labor Statistics computes these semi-aggregated expenditure items from the more finelydetailed expenditure information collected by the survey, and puts them in the "summary expenditure section" of the CEX data tape. It should be noted that "housing" is broadly defined to include utilities, household furnishings and household equipment. Furthermore, the cost of an owner-occupied house is measured as actual interest payments on mortgages, and not as the rental value of the house. This definition of total expenditure is the conditioning variable in our Engel curves, and when we calculate the compensation required to restore adult expenditures to pre-child levels, it is the increase in this measure of the total that is used. The validity of the procedure requires that additional children have no effect on total expenditure, so that we are ignoring effects of children on income through changes in labor supply, as well as on saving. To the extent that children decrease this definition of total expenditure-which seems the more probable outcome-the costs of children will be understated by the amount of the decrease.

In this section and the next, we start with a non-parametric analysis, to explore whether the data are at all consistent with the underlying hypothesis, and then use the results to suggest the more parametric forms that allow the inclusion of a wider range of covariates. For the analysis of adult goods and child costs, the nonparametric analysis adopts the obvious procedure of fitting adult good Engel curves for different family types, comparing households with and without children. The CEX sample will support such an analysis for a limited number of family types; Table 3.1 lists the number of families by combinations of adults and children. Given these, it makes sense to fit nonparametric regressions for adult, children combinations of $(1,0),(1,1)$, $(1,2),(2,0),(2,1),(2,2),(2,3),(3,1)$, and $(3,2)$. We do this by calculating the regression function of adult expenditures (in $\$$ per month) conditional on the logarithm of total annual expenditure using a version of Fan's (1992) local regression smoother. In order to exclude areas of low density at the extremes of rich and poor, we trim the sample to the range of log total outlay 
shown, and then erect a 100 point uniform grid over log outlay. At each point $x$ on this grid, we run a weighted regression with weights given by the quartic kernel:

$$
\begin{aligned}
w_{i} & =\frac{15}{16} \lambda_{i}\left(1-t_{i}^{2}\right)^{2} ; \quad\left|t_{i}\right| \leq 1 \\
& =0 ; \quad\left|t_{i}\right|>1
\end{aligned}
$$

where $t_{i}$ is the distance of $x_{i}$ from $x$ in units of the bandwidth $h$,

$$
t_{i}=\left(x-x_{i}\right) / h \text {. }
$$

The bandwidth $h$ is chosen by visual inspection of alternative estimates in an attempt to preserve genuine structure while eliminating random fluctuations. The multiplier $\lambda i$ is an inflation factor, provided in the CEX, that accounts for the fact that the $\mathrm{CEX}$ is not a simple random sample. For each observation $i, \lambda i$ is equal to the number of households in the US population the observation represents, so that observations that represent more households are given more weight in the regressions.

The results are shown in Figure 3.1 for one adult, two adult, and three adult non-poor families. The restriction to families above the poverty line is because families in poverty have very different consumption patterns, as we shall see in the next subsection. Although the ordering of the curves is not uniformly monotone over the range of total outlay, the ordering is generally in the right direction, and certainly so in the middle of the total expenditure distribution. Holding total expenditure constant, the addition of children reduced expenditure on adult goods. Note also that the slopes of the regression functions are positive, a condition that must be satisfied if we are to calculate the variations in total expenditure that would have equivalent effects on adult expenditure to the addition of children. It is also a condition that is often not satisfied in practice, see for example Cramer (1969).

The curves in Figure 3.1 are close to one another so that the estimates of child costs that they imply are relatively modest. The mean of $\log$ outlay for $(1,0)$ households is 8.06 ; conditional on this, adult expenditure is predicted to be $\$ 252$ a month. To have the same predicted adult expenditure, a $(1,1)$ household would need a $\log$ outlay of 8.34 , and a $(1,2)$ household 8.52 . One child costs 28 percent of a single adult, and two children (together) 46 percent of an adult. For a $(2,0)$ family, and additional child is 32 percent of one adult, two children 72 percent, and three children 76 percent. For three adult families, the first child costs 54 percent of one adult, two children 90 
percent of an adult. While these numbers might make sense for India or a similarly poor country, they seem unreasonably small for the US.

Alcohol and tobacco are two items that are notoriously underestimated in household expenditure surveys including the CEX, so that it is wise to re-estimate the results using only adult clothing and footwear. But the results are very similar; if anything child costs are estimated to be somewhat lower. This echoes Betson's (1990) findings that the results are not much affected by the choice of the broad or narrow definition of adult expenditures. Another potential source of underestimation is that children consume some of the adult goods. If so, the addition of the child will have a direct positive effect on consumption as well as the negative income effect, so that expenditure on adult goods will be reduced by too little, and child costs underestimated. For alcohol, tobacco, and adult clothing, this is unlikely to be a problem for young children, but may well be serious for teenagers. However, it is difficult to allow for child age in the nonparametric regressions, so we move to a flexible parametric model.

Our general approach, both for the investigation of child costs and economies of scale, is to allow total expenditure to enter the regression function in a general way, while other variables enter linearly. There is a great deal of information in the data about the shape of the Engel curve, and it is desirable to use it. Because family size and compositional variables are correlated with total expenditure, a failure to model the shape of the Engel curve is likely to compromise the estimates in which we are interested. The model we estimate is written

$$
e_{A}=f(\ln x)+\beta_{1} \ln n+\sum_{k=1}^{K} \gamma_{k} \frac{n_{k}}{n}+u
$$

where $e_{A}$ is expenditure on adult goods, $n$ is household size, $x$ is total outlay, and $n_{k}$ is the number of people in the $k$ th age-sex category in the household. The right hand side is motivated by the wish to approximate the 'obvious' but nonlinear form

$$
e_{A}=\phi\left(\frac{x}{\left(A+\sum \alpha_{j} k_{j}\right)^{\theta}}\right)
$$

which, with an extension to different types of children, is the form with which we began. 
We proceed as follows. Equation (3.10) is first estimated with per capita outlay entered linearly, followed by the Fourier specification

$$
f(t)=\sigma_{0}+\sigma_{1} t+\sigma_{2} t^{2}+\sum_{i=1}^{M}\left(\sigma_{c i} \cos (i t)+\sigma_{s i} \sin (i t)\right)
$$

for which we have generally found that setting $M$ to 2 is adequate. The equation is estimated for both narrow (clothing) and broad (clothing, alcohol, and tobacco) definitions of adult goods, and is estimated separately for one adult, two adult, and three adult households. Family composition is disaggregated by age and sex, so that we have males and females aged $0-5,6-11,12-17,18-64$, and 65 and older. Since the ten ratios sum to one, we omit that associated with females aged 65 and over, which therefore becomes the reference group.

The regression results which are not shown in detail, but a few points are worth noting since they affect the calculations of child costs. The Fourier approximation always improves the fit but the effects on the other parameter estimates are modest, so that we can focus on the more easily interpreted linear form. Clothing and footwear has an expenditure elasticity that is greater than unity, in contrast to the broad aggregate, which is dominated by alcohol and tobacco, the share of which declines with total outlay. The compositional effects work more or less as anticipated. As is required for the model to make any sense, additional prime age adults increase expenditure on adult goods, although it is adult women who spend most on adult clothing, with little effect for men. Additional children decrease expenditure on adult goods, or at least they do until they are 12 years old, at which point they smoke and drink, and if they are girls, buy adult clothing. We clearly cannot use expenditure on these goods to estimate the costs of older children.

Table 3.2 presents the estimates of child equivalences, calculated separately according to whether we are using all adult expenditure, or just clothing, whether we are using the Fourier approximation or the linear model, according to the number of adults, and according to the age and sex of the additional child. The numbers are calculated as follows. In the top panel, we consider the addition of a child to a family containing a single adult female aged between 18 and 64. By (3.10) if $f($.$) has the linear form \alpha+\beta \ln x$, adult expenditure in the new larger household 
will be the same as in the original smaller household if, when the original household has expenditure $x$, the new one has expenditure $x$ "given by

$$
\ln \frac{x^{*}}{x}=\beta^{-1}\left(\beta_{1} \ln \frac{1}{2}+\frac{\gamma_{a f}}{2}-\frac{\gamma_{j}}{2}\right)
$$

where $\gamma_{a f}$ is the coefficient of the adult female ratio and $\gamma_{j}$ is the coefficient of the child ratio in which we are interested. The top panel in the Table shows $\ln \left(x^{*} / x\right)-1$ the proportional additional cost of the child. For the two adult family, the corresponding formula is

$$
\ln \frac{x^{*}}{x}=\beta^{-1}\left(\beta_{1} \ln \frac{2}{3}+\frac{\gamma_{a f}}{6}+\frac{\gamma_{a m}}{6}-\frac{\gamma_{j}}{3}\right)
$$

where $\gamma_{a m}$ is the adult male coefficient, and the numbers presented in the table are scaled, i.e. $2\left(\ln \left(x^{*} / x\right)-1\right)$ in order to present the child cost relative to a single adult, rather than a couple. The three adult household is taken to be an adult male, and adult female, and an elderly female, and the costs are calculated in the corresponding way. When the Fourier approximation to the Engel curve is used, it is no longer possible to derive a closed-form expression for child costs. Instead, we use as an approximation (3.13) and (3.14) with $\beta$ replaced by the derivative of the Engel curve with respect to log expenditure evaluated at the mean of log total expenditure. We make no attempt to calculate child costs for children other than the first. While such calculations are straightforward in principle, the differences from the cost of the first child are effectively determined by the choice of functional form (3.10), rather than by any genuine feature of the data.

In terms of the broad orders of magnitude with which we are concerned, the child cost estimates in Table 3.2 are sensitive to neither the choice of functional form for the Engel curve nor to the broad or narrow definition of adult goods. As expected, the estimates for the older children are much too low; 'children' between 12 and 17 clearly consume these 'adult' goods. But the differentiation by age has solved the underestimation problem in the nonparametric results, so that children under 12 appear to cost around two-thirds to three-quarters of an adult. Comparing the results for single adult to two adult families, there is not much evidence of the reduction in child costs that would be expected from economies of scale, although the estimates based on clothing 
are lower for the smallest children. However, child costs do seem to be lower for the three adult households. Even so, we could not obtain useful results by following the NAS procedure and identifying economies of scale by matching the numbers in the table to the ratio of $(A+\alpha K)^{\theta}$ to $A^{\theta}$ with $K=1$. To measure economies of scale, we must turn to more direct methods.

\subsection{Using private goods and economies of scale}

In this subsection we report our attempts to obtain estimates of economies of scale by looking at the relationship between expenditure on private goods, expenditure per head, and family size. The basic idea is illustrated in Figure 3.2 which shows the relationship between expenditure per capita on private goods - or on any single private goods or group of private goods-and income (or total expenditure) per head. The lower curve is the private good Engel curve for the smaller household with $n_{1}$ members, all of whom are assumed to be adults. Consider an increase to $n_{2}$ adults with per capita income held constant, for example when two single adults get married. Since they have the same total resources as before, it is possible for them to keep their consumption pattern unchanged. However, we would not expect this to happen since the larger family thereby ignores the potential economies of scale associated with public goods. Since the nature of public goods is that they do not have to be duplicated for each household member, the larger household need spend less on them, freeing up more resources from private goods, so that the Engel curve moves upward as shown. The graph shows the amount $\delta$ by which per capita income must be reduced so as to restore private expenditures to their previous per capita level. If this amount were deducted from the income of the larger family, it would still be better off than the smaller family, since a correctly compensated family would presumably take advantage of the relative cheapness of public goods to substitute in their favor, and would therefore spend less on private goods. The calculation of $\delta$ therefore understates the discount from the economies of scale. It would be possible to correct for this underestimation by estimating a full demand system that allows for the price like effects of economies of scale as in Nelson (1991), the understatement can be minimized by selecting a private good that is a relatively poor substitute for the public 
goods in the household. For example, people are unlikely to substitute housing and utilities for food just because utility is cheaper through the former the larger is household size.

We therefore began our investigations with food. Although there may be some economies of scale associated with food-bulk buying, reduction of wastage, and saving on items such as cooking oil that are used less than proportionately with scale-the effects seem likely to be modest. There is the further advantage that food is a poor substitute for the most likely public goods. Nevertheless, to our considerable surprise, expenditure on food does not behave as illustrated in Figure 3.2. Holding constant per capita outlay, per capita expenditure on food decreases with family size, which suggests that the larger the family, the less food each member needs to remain equally well off. Our preliminary investigations for India, for Britain, for Taiwan, and for South Africa, suggest that this result is true much more broadly than for the US; the results in Lanjouw and Ravallion (1992) and Ayadi, Baccouche, Goiaed and Matoussi (1995) appear to show the same result in Pakistan and Tunisia respectively. The detailed evidence would take us too far afield from our main purpose, and we plan to make a fuller report elsewhere. Here we confine ourselves to the main results for the US, to some possible explanations, and to the search for economies of scale through other potential private goods.

Figure 3.3 shows the locally weighted nonparametric regressions for the food share conditional on the logarithm of per capita expenditure for households with one to four non-elderly adults and zero children. Although the argument in Figure 3.2 was presented in terms of per capita food expenditure increasing with family size, the same argument applies to the food share in the budget, which is the ratio of per capita food expenditure to per capita total expenditure, and the latter is being held constant as family size is changed. Although the relationship between the four curves changes with the level of per capita outlay, the one adult curve is highest through most of the range, and the four adult curve is the lowest. The curves for two and three adults are close to one another and cross more than once. At the same level of per capita outlay, one adult households spend more per capita on food than do two or three adult households, who in turn spend more than four adult households. While it is possible to think of reasons why one adult families are special - they may eat out a great deal, or they buy expensive pre-cooked food, or they waste a great deal of food-it is hard to reconcile the results for the other family types with 
the presumption that food is a private good and that economies of scale operate through non-food public goods.

In order to investigate whether the same phenomenon holds for more complex family types, and survives the conditioning on a wider range of variables, we once again have to move to a more parametric treatment. In parallel with our earlier discussion of child costs and adult goods, we adopt a flexible functional form for the food budget share of the form:

$$
w_{f}=f\left(\ln \frac{x}{n}\right)+\beta_{1} \ln n+\sum_{k=1}^{K} \gamma_{k} \frac{n_{k}}{n}+\psi \pi+u
$$

where $w_{f}$ is the food share, and $\pi$ is a dummy indicating whether or not the family falls below the official poverty line, a dummy that is provided on the CEX tape. Although not shown in (3.15), we also interact household size and the demographic compositional variables with the poverty dummy. This is done, not because poverty itself changes demand patterns-and if it did, the effect would be picked up by a sufficiently flexible function $f($.$) -but because families in poverty,$ depending on their demographic composition, are entitled to food stamps, housing benefits, and other programs that are likely to change their consumption patterns.

As before, we treat the function $f($.$) in more than one way; (a)$ using the linear specification $\alpha+\beta_{0} \ln x / n,(b)$ using the Fourier flexible form (3.12), and (c) by following a nonparametric technique of Estes and Honore (1995). The last works by first sorting the data in according to the values of $x / n$, and then fitting (3.15) by OLS to the fist-difference of all the right-hand side variables excluding $x / n$. As the sample size increases, and provided that the function $f($.$) is continuous,$ the distance between any two successive values decreases at rate $n^{-1}$ so that, in the limit, the influence of $x / n$ is purged from the regression, as if it were a (local) fixed effect. The advantage of this procedure-apart from its elegance and simplicity-is that we do not have to specify any functional form. The disadvantage is that we do not obtain an estimate of the slope of the Engel curve, something that is of no importance when our aim is to find the sign of $\beta_{1}$, the coefficient on family size, but which would be become necessary if we ever got as far as calculating the compensation as in Figure 3.2. 
The three sets of results are presented in Table 3.3. In the event, getting the shape of the Engel curve right has little effect on the other coefficients, and in all three specifications, the budget share of food is reduced by between a full point and two-thirds of a point in response to a unit increase in the logarithm of family size. This is not a large effect, but the negative sign is statistically significant, and once again we have the reverse of what would be predicted by our description of economies of scale. The other coefficients in Table 3.3 are of some independent interest. Controlling for per capita outlay, children, whether boys or girls, reduce per capita food consumption, and men spend more on food than do women. The poverty dummy has strong positive interactions with the presence of children under the age of 12 , presumably through the operation of food stamps and AFDC.

We have no good explanation for the failure of food to behave like a private good. Perhaps there are substantial economies of scale, or perhaps increases in family size cause more substitution than seems plausible from food towards housing and other public goods. Whatever the story, the conclusion that a negative discount understates the true discount to family size, although hard to challenge, is not very useful. We therefore turn to other goods as potential private goods, although we confess that our confidence in the general methodology is somewhat shaken by the failure of the most promising good to yield useful results.

As for food, we estimate (3.15) for a range of goods from the CEX. We calculate the change in the logarithm of per capita total outlay that keeps per capita expenditure constant in the face of a change in household size with household composition held constant. This is done through the per capita expenditure-constant elasticity, from (3.15)

$$
\frac{d \ln x / n}{d \ln n}=\frac{\beta_{1}}{w+f^{\prime}(\ln x / n)}
$$

which is evaluated at the sample means.

The results, in Table 3.4, are given for a list of commodity groups that sums to total outlay, and are almost as bewildering as those for food. Of course, goods like transportation, housing and utilities are certainly not private goods, and it is no surprise to find that expenditure per capita on housing falls with family size. But commodities like alcohol and tobacco, which might seem to be 
candidates for private goods, have less spent on them as family size increases. Perhaps these are examples of negative public goods, that generate negative externalities for other members of the family, and which therefore become more expensive as family size increases. Transportation and medical expenditures - the latter strongly associated with the elderly in the estimates-are items whose expenditure increases with family size. The former would appear to have a public element, in which case its expenditure would be expected to decrease, while it is hard to see why family size should increase medical expenditures when the age composition of the household is being controlled for. There is perhaps some consolation in the estimates for clothing, personal care, and educational expenditures. If we use these, and ignore the anomalous results elsewhere, we obtain modest economies of scale, with the elasticity of needs to size between 85 and 95 percent. But it is hard to escape the conclusion that expenditure patterns respond to family size in ways that are a good deal more complex than the simple story of public and private goods that we have considered in this paper. Constructing better models of this process remains a challenge for the future.

\section{References}

Ayadi, Mohamed, Rafiq Baccouche, Mohamed Goaid and Mohamed Matoussi, (1995), 'Spatial variations of prices and household demand analysis in Tunisia,' University of Tunis III, Faculté des Sciences Economiques et de Gestion de Tunis, processed. (Jan.) Barten, Anton P., 1964, 'Family composition, prices, and expenditure patterns,' in Peter Hart, Gordon Mills, and John Whitaker, eds., Economic analysis for national economic planning, London. Butterworth.

Betson, David M., 1990, 'Alternative estimates of the cost of children from the 1980-86 consumer expenditure survey,' Madison, WI. Institute for Research on Poverty, Special Report \# 51.

Cramer, Jan S., 1969, Empirical econometrics, Amsterdam, North-Holland.

Deaton, Angus S., and John Muellbauer, 1980, Economics and consumer behavior, New York. Cambridge University Press.

Deaton, Angus S., and John Muellbauer, 1986, 'On measuring child costs,' Journal of Political Economy, 94, 720-44. 
Deaton, Angus S., and Christina H. Paxson, 1995, 'Measuring poverty among the elderly in India,' Princeton, NJ. Research Program in Development Studies, processed. (Jan.)

Estes, Eugena M. and Bo E. Honoré, 1995, "Partial regression using one nearest neighbor," Princeton University (in progress).

Fan, Jianqing, 1992, 'Design-adaptive nonparametric regression,' Journal of the American Statistical Association, 87, 998-1004.

Geiseman, Raymond, 1987, 'The consumer expenditure survey: quality control by comparative analysis,' Monthly Labor Review, March, 8-14.

Government of India, 1993, Report of the Expert Group on Estimation of Proportion and Number of Poor, Perspective Planning Division, Planning Commission, New Delhi, July.

Haddad, Lawrence and S. Ravi Kanbur, 1990, 'How serious is the neglect of inta household inequality,' Economic Journal, 100, 866-81.

Lanjouw, Peter and Martin Ravallion, 1993, 'Are larger households really poorer?' Washington, D.C. The World Bank, Policy Research Department.

Lazear, Edward P., and Robert T. Michael, 1988, The allocation of income within the household, Chicago, IL. University of Chicago Press.

National Research Council, 1995, Measuring poverty: a new approach. Washington, D.C. National Academy Press.

Nelson, Julie A., 1988, 'Household economies of scale in consumption: theory and evidence,' Econometrica, 56, 1301-14.

Nicholson, J. Leonard, 1976, 'Appraisal of different methods of estimating equivalence scales and their results,' Review of Income and Wealth, 22, 1-18.

OECD, 1982, The OECD list of social indicators. Paris: OECD.

Pollak, Robert A., and Terence J. Wales, 1979, 'Welfare comparisons and equivalence scales,' American Economic Review (papers and proceddings), 216-21.

Rothbarth, Erwin, 1943, 'Note on a method of determining equivalent income for families of different composition, in Charles Madge, ed., War time pattern of saving and spending, Cambridge. Cambridge University Press.

Ruggles, Patricia, 1990, Drawing the line, Washington, D.C. Urban Institute Press. 
Slesnick, Daniel T., 1993, 'Gaining ground: poverty in the postwar United States,' Journal of Political Economy, 101, 1-38. 
Table 2.1: US poverty lines, 1992

\begin{tabular}{|l|ccccc|}
\hline \multirow{2}{*}{ Size of family } & \multicolumn{5}{|c|}{ Related children under 18 years } \\
& None & One & Two & Three & Four \\
\hline One person: & & & & \\
under 65 years & 7,299 & & & \\
65 years and over & 6,729 & & & \\
& & & & \\
Two persons, with & & & & \\
householder: & 9,395 & 9,670 & & \\
under 65 years & 8,480 & 9,634 & & \\
65 years and over & & & & \\
& 10,974 & 11,293 & 11,304 & 14,277 & \\
Three persons & 14,471 & 14,708 & 14,228 & 16,487 \\
Four persons & 17,451 & 17,705 & 17,163 & 19,743 & \\
Five persons & 20,072 & 20,152 & 19,737 & 19,339 & \\
Six persons & & & & & \\
& & & & \\
\end{tabular}

Notes: These poverty lines are reproduced from U.S. Bureau of the Census (1993), Boverty in the United States: 1992. Table A, page vii.

Table 2.2: Poverty rates for elderly, non-elderly adults, and children in the US

\begin{tabular}{|l|r|r|r|r|}
\hline & \multicolumn{1}{|c|}{ All people } & \multicolumn{1}{|c|}{ Children < 18 } & Adults 18-64 & Adults 65+ \\
\hline & \multicolumn{4}{|c|}{ Using family-level data } \\
\hline Sample size & 154,977 & 42,869 & 93,069 & 19,039 \\
Estimated population ('000's) & 253,924 & 67,062 & 156,035 & 30,827 \\
Number poor ('000's) & 36,987 & 14,846 & 18,174 & 3,968 \\
\% in poverty & 14.57 & 22.14 & 11.65 & 12.87 \\
\hline & \multicolumn{4}{|c|}{ Using household-level data } \\
\hline Number poor ('000's) & 33,311 & 13,800 & 15,696 & 3,815 \\
\% in poverty & 13.12 & 20.58 & 10.06 & 12.38 \\
\hline
\end{tabular}

Notes: The data used for this table are from the March 1993 Current Population Survey, which records 1992 income. The sample consists of all individuals who do not live in group quarters. The population weights from the "person" records were used to obtain population estimates. A person was defined to be poor if his or her family income (in the top panel) or household income (in the bottom panel) was below the relevant poverty line for his or her family (top panel) or household (bottom panel). 
Table 2.3: Poverty rates for elderly and non-elderly people in India

\begin{tabular}{|l|lll|lll|}
\hline & Rural & & & Urban & & \\
\hline & All & $\begin{array}{l}\text { Non- } \\
\text { elderly }\end{array}$ & Elderly & All & $\begin{array}{l}\text { Non- } \\
\text { elderly }\end{array}$ & Elderly \\
\hline Gujarat & 42.19 & 42.88 & 31.28 & 26.73 & 26.91 & 23.60 \\
Kamataka & 54.06 & 54.40 & 48.98 & 40.83 & 41.06 & 37.31 \\
Kerala & 30.36 & 30.77 & 25.97 & 35.16 & 35.56 & 30.81 \\
Maharashtra & 53.33 & 53.63 & 49.19 & 26.54 & 26.62 & 25.15 \\
Madhya Pradesh & 61.13 & 61.55 & 54.52 & 35.75 & 35.78 & 35.27 \\
Tamil Nadu & 54.46 & 54.85 & 49.54 & 33.89 & 33.96 & 32.94 \\
\hline
\end{tabular}

Note: This table presents poverty head-count ratios, i.e. the percentage of people who are poor. A person is counted as poor if he or she lives in a household with per capita expenditure that is less than or equal to a poverty line. The poverty lines are 131.8 rupees per person per month for rural areas, and 152.1 rupees per person month in urban areas. A person is defined as "elderly" if he or she is aged 60 or older.

Table 2.4: Poverty rates in the US with the old-age discount removed from poverty lines

\begin{tabular}{|l|r|r|r|r|}
\hline & \multicolumn{1}{|c|}{ All people } & \multicolumn{1}{c|}{ Children < 18} & Adults 18-64 & Adults 65+ \\
\hline & \multicolumn{4}{|c|}{ Using family-level data } \\
\hline Sample size & 154,977 & 42,869 & 93,069 & 19,039 \\
Estimated population ('000's) & 253,924 & 67,062 & 156,035 & 30,827 \\
Number poor ('OOO's) & 37,745 & 14,848 & 18,213 & 4,684 \\
\% in poverty & 14.86 & 22.14 & 11.67 & 15.19 \\
\hline & \multicolumn{4}{|c|}{ Using household-level data } \\
\hline Number poor ('OOO's) & 34,062 & 13,800 & 15,736 & 4,526 \\
\% in poverty & 13.41 & 20.58 & 10.08 & 14.68 \\
\hline
\end{tabular}


Table 2.5a: Family and household composition in the US

\begin{tabular}{|l|r|r|r|}
\hline & Children & Non-elderly adults & Elderly adults \\
\hline \multicolumn{5}{|c|}{ Family-level data } \\
\hline number of children & 2.39 & .86 & .08 \\
number of non-old adults & 1.95 & 2.10 & .36 \\
number of old adults & .04 & .08 & 1.50 \\
children+adults & 4.38 & 3.04 & 1.94 \\
children/(children+adults) & .533 & .203 & .017 \\
\hline \multicolumn{5}{|c|}{ Household-level data } \\
\hline number of children & \multicolumn{5}{|c|}{2.42} & .90 & .09 \\
number of non-old adults & 2.02 & 2.23 & .38 \\
number of old adults & .037 & .08 & 1.51 \\
children+adults & 4.81 & 3.21 & .98 \\
children/(children+adults) & .524 & .208 & .018 \\
\hline
\end{tabular}

Note: The table shows averages, across all people in the relevant age category, of family (top panel) and household (bottom panel) characteristics. For example, the children live in families that contain, on average, 2.39 children.

Table 2.5b: Household composition in India

\begin{tabular}{|l|l|l|l|l|}
\hline Average: & Rural non-elderly & Rural elderly & Urban non-elderly & Urban elderly \\
\hline Number of children & 3.70 & 3.98 & 3.81 & 4.39 \\
Number of adults & 2.55 & 1.75 & 2.23 & 1.57 \\
Children+adults & 6.25 & 5.73 & 6.04 & 5.96 \\
children/(children+adults) & .386 & .236 & .348 & .211 \\
\hline
\end{tabular}

Note: See note to table 2.5 a. 
Table 2.6: US Poverty rates using different base household types

\begin{tabular}{|l|r|r|r|r|r|r|}
\hline & \multicolumn{3}{|c|}{ 2-adult 2-child base } & \multicolumn{3}{c|}{ 1-adult base } \\
\hline & children & $\begin{array}{c}\text { non-elderly } \\
\text { adults }\end{array}$ & $\begin{array}{c}\text { elderly } \\
\text { adults }\end{array}$ & children & $\begin{array}{c}\text { non-elderly } \\
\text { adults }\end{array}$ & $\begin{array}{c}\text { elderly } \\
\text { adults }\end{array}$ \\
\hline$\alpha=1.3, \theta=.47$ & 22.02 & 11.46 & 14.40 & 23.04 & 12.28 & 16.08 \\
$\alpha=1.0, \theta=.47$ & 21.84 & 11.97 & 16.54 & 21.60 & 11.81 & 15.97 \\
$\alpha=0.7, \theta=.47$ & 21.61 & 12.66 & 19.60 & 19.49 & 11.11 & 15.90 \\
$\alpha=1.3, \theta=.75$ & 22.36 & 9.75 & 5.79 & 35.51 & 18.21 & 20.29 \\
$\alpha=1.0, \theta=.75$ & 22.07 & 10.29 & 7.72 & 31.86 & 16.89 & 20.22 \\
$\alpha=0.7, \theta=.75$ & 21.62 & 11.03 & 11.04 & 27.90 & 15.48 & 20.12 \\
\hline
\end{tabular}

Table 3.1: CEX 1990, numbers of households by composition

\begin{tabular}{|r|r|r|r|r|r|}
\hline AdultsKids & 0 & 1 & 2 & 3 & 4 \\
\hline 1 & 5567 & 554 & 371 & 165 & 48 \\
2 & 5452 & 1943 & 2047 & 953 & 258 \\
3 & 1195 & 463 & 255 & 126 & 47 \\
4 & 406 & 146 & 57 & 52 & 9 \\
5 & 94 & 48 & 21 & 13 & 5 \\
\hline
\end{tabular}


Table 3.2: Estimated child costs relative to single adults for various family types by child age and sex (percent)

\begin{tabular}{|l|l|l|l|l|}
\hline & \multicolumn{2}{l|}{ all adult expenditures } & \multicolumn{2}{l|}{ adult clothing and footwear } \\
\hline & linear form & flexible form & linear form & flexible form \\
\hline Adult female plus & & & & \\
boy 0-5 & 69 & 65 & 90 & 81 \\
girl 0-5 & 70 & 67 & 98 & 91 \\
boy 6-11 & 62 & 69 & 53 & 58 \\
girl 6-11 & 54 & 63 & 72 & 81 \\
boy 12-17 & 68 & 71 & 66 & 66 \\
girl 12-17 & 33 & 45 & 27 & 39 \\
\hline Adult couple plus & & & & \\
boy 0-5 & 70 & 82 & 53 & 60 \\
girl 0-5 & 72 & 82 & 62 & 68 \\
boy 6-11 & 76 & 63 & 76 & 66 \\
girl 6-11 & 80 & 42 & 22 & 85 \\
boy 12-17 & 36 & 19 & -5 & 24 \\
girl 12-17 & 15 & & & -6 \\
\hline Three adults plus & & 54 & 65 & \\
boy 0-5 & 60 & 57 & 73 & 58 \\
girl 0-5 & 60 & 59 & 28 & 37 \\
boy 6-11 & 52 & 52 & 48 & 57 \\
girl 6-11 & 43 & 61 & -1 & 13 \\
boy 12-17 & 58 & 33 & & \\
girl 12-17 & 19 & & & \\
\hline
\end{tabular}

Notes: The three adult household is an adult male, and adult female, and a female aged 65 or over. The calculations for the linear form are exact, those for the flexible Fourier form are approximations. 
Table 3.3: Food share regressions using three alternative techniques

\begin{tabular}{|c|c|c|c|c|c|c|}
\hline & \multicolumn{2}{|l|}{ linear form } & \multicolumn{2}{|c|}{ Fourier flexible form } & \multicolumn{2}{|c|}{$\begin{array}{l}\text { Estes and Honoré } \\
\text { nonparametric }\end{array}$} \\
\hline $\ln x / n$ & -7.25 & (39.3) & * & * & $\dagger$ & + \\
\hline $\ln n$ & -0.71 & (2.9) & -0.67 & $(2.7)$ & -0.95 & $(4.6)$ \\
\hline $\mathrm{rm} 05$ & -7.28 & (7.3) & -7.48 & $(7.6)$ & -7.58 & $(7.8)$ \\
\hline rm611 & -1.08 & $(1.0)$ & -1.27 & $(1.2)$ & -0.85 & $(0.8)$ \\
\hline $\mathrm{rm} 1217$ & 2.86 & (2.5) & 2.78 & $(2.4)$ & 2.21 & (2.1) \\
\hline $\mathrm{rm} 1864$ & 2.36 & (5.2) & 2.10 & $(4.8)$ & 2.13 & (5.7) \\
\hline $\mathrm{rm} 65$ & 3.34 & $(4.6)$ & 3.29 & $(4.5)$ & 3.20 & (5.5) \\
\hline rf05 & -9.22 & (9.1) & -9.41 & $(9.2)$ & -9.54 & (9.5) \\
\hline rf611 & -2.73 & (2.7) & -2.70 & $(2.8)$ & -1.32 & (1.2) \\
\hline rf 1217 & 1.14 & (1.0) & 0.90 & $(0.8)$ & 0.24 & $(0.2)$ \\
\hline rf 1864 & -1.22 & (2.9) & -1.22 & $(2.9)$ & -0.99 & $(2.7)$ \\
\hline$\pi * r m 05$ & 11.27 & (3.9) & 9.62 & (3.3) & 10.14 & $(4.6)$ \\
\hline$\pi^{*} \operatorname{mm} 611$ & 6.16 & $(2.1)$ & 4.77 & (1.6) & 5.14 & (2.3) \\
\hline$\pi^{*} \operatorname{rm} 1217$ & 2.87 & $(1.0)$ & 1.14 & $(0.4)$ & -0.80 & $(0.3)$ \\
\hline$\pi^{*} \operatorname{rm} 1864$ & -1.73 & (1.4) & -1.62 & $(1.3)$ & -1.08 & (1.3) \\
\hline$\pi^{*} \mathrm{rm} 65$ & -3.90 & (2.3) & -3.93 & (2.3) & -3.63 & (2.7) \\
\hline$\pi * \mathrm{rf05}$ & 6.80 & (2.5) & 5.27 & $(2.0)$ & 6.76 & (3.1) \\
\hline$\pi^{*} \mathrm{r}$ 611 & 6.97 & (1.8) & 5.31 & $(1.4)$ & 4.66 & $(2.0)$ \\
\hline$\pi^{*} \mathrm{rf} 1217$ & -1.38 & $(0.5)$ & -2.15 & $(0.7)$ & 1.64 & $(0.7)$ \\
\hline$\pi^{*} \operatorname{rf1} 1864$ & -1.42 & (1.4) & -1.31 & $(1.3)$ & -1.53 & $(1.9)$ \\
\hline$\pi$ & 1.01 & $(2.2)$ & 1.61 & $(2.0)$ & 1.03 & (1.7) \\
\hline
\end{tabular}

Notes: * estimated by Fourier flexible form and coefficients not shown. $\dagger$ estimated as a local fixed effect and eliminated from the regression. All coefficients multiplied by 100 . Absolute values of t-statistics are in parentheses. For the first two columns, the standard errors on which the t-statistics are based have been corrected for random household effects. (Recall that the CEX has a panel element, and a single household may contribute up to 4 observations.) The Estes and Honoré standard errors have not been corrected for the first-differencing or for household random effects.

Table 3.4: Family size percentage discounts for various items of expenditure

\begin{tabular}{|l|c|c|}
\hline commodity group & discount using linear form & discount using flexible form \\
\hline food & -4.5 & -4.4 \\
alcohol & -82.4 & -69.0 \\
tobacco & -60.6 & -88.6 \\
clothing & 5.6 & 5.9 \\
transportation & 20.3 & 19.9 \\
housing and utilities & -10.6 & -10.3 \\
entertainment & 9.8 & 9.8 \\
personal care & 9.1 & 8.9 \\
medical expenditures & 31.0 & 36.6 \\
reading material & -8.6 & -7.7 \\
educational expenditures & 17.2 & 16.7 \\
\hline
\end{tabular}


cumulative distributions

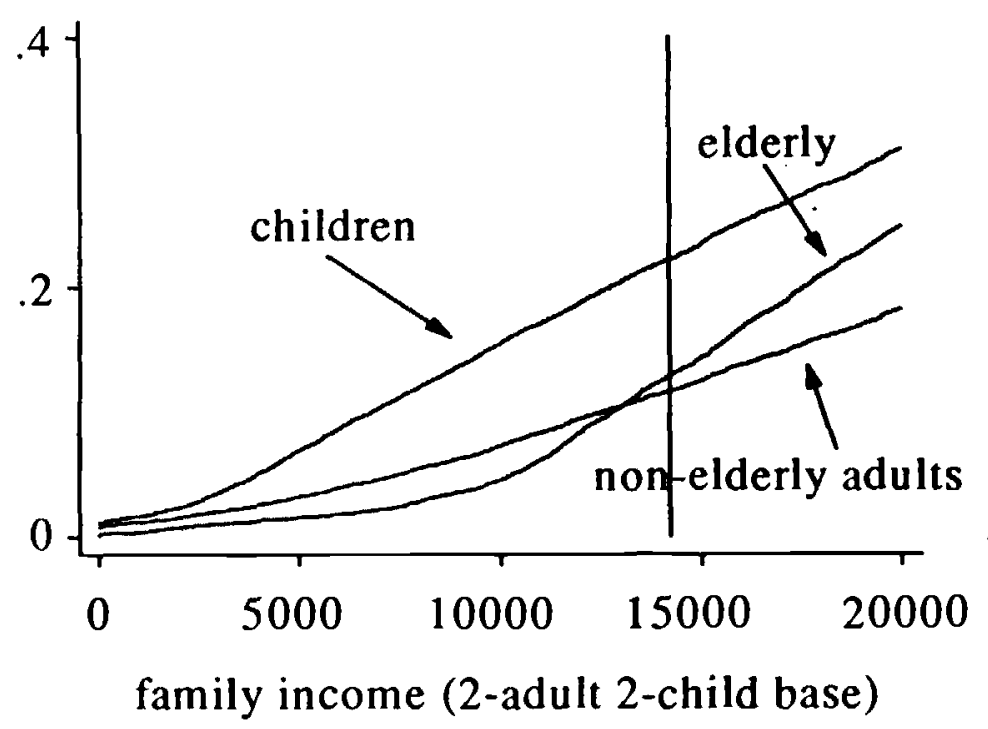

differences in cumulative distributions

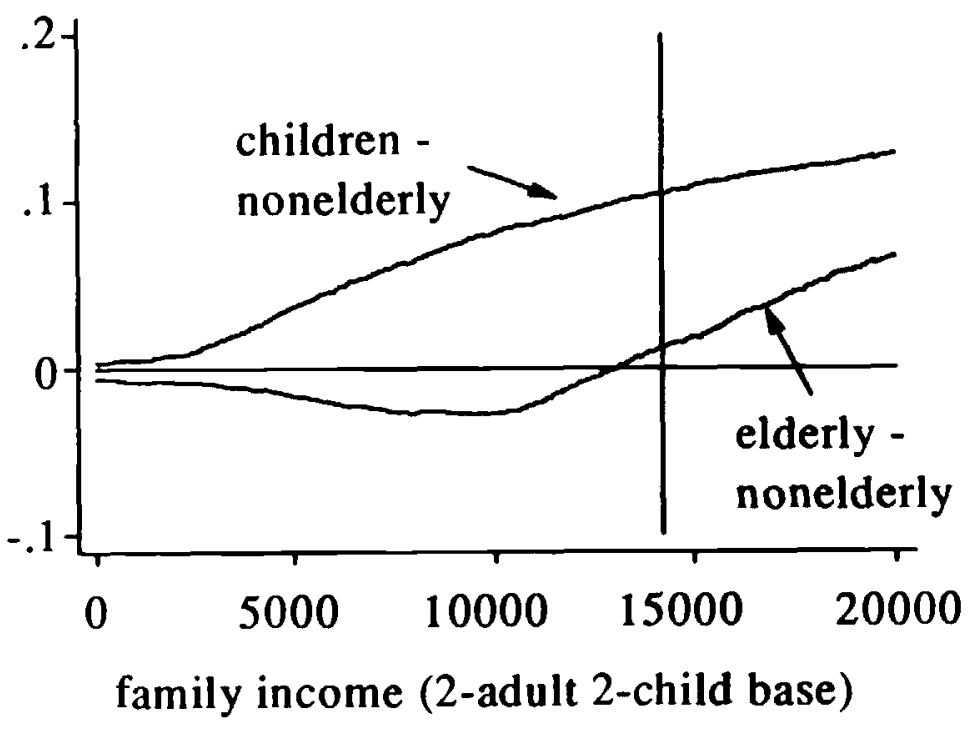

Figure 2.1: Cumulatives of family income by age group in the US 

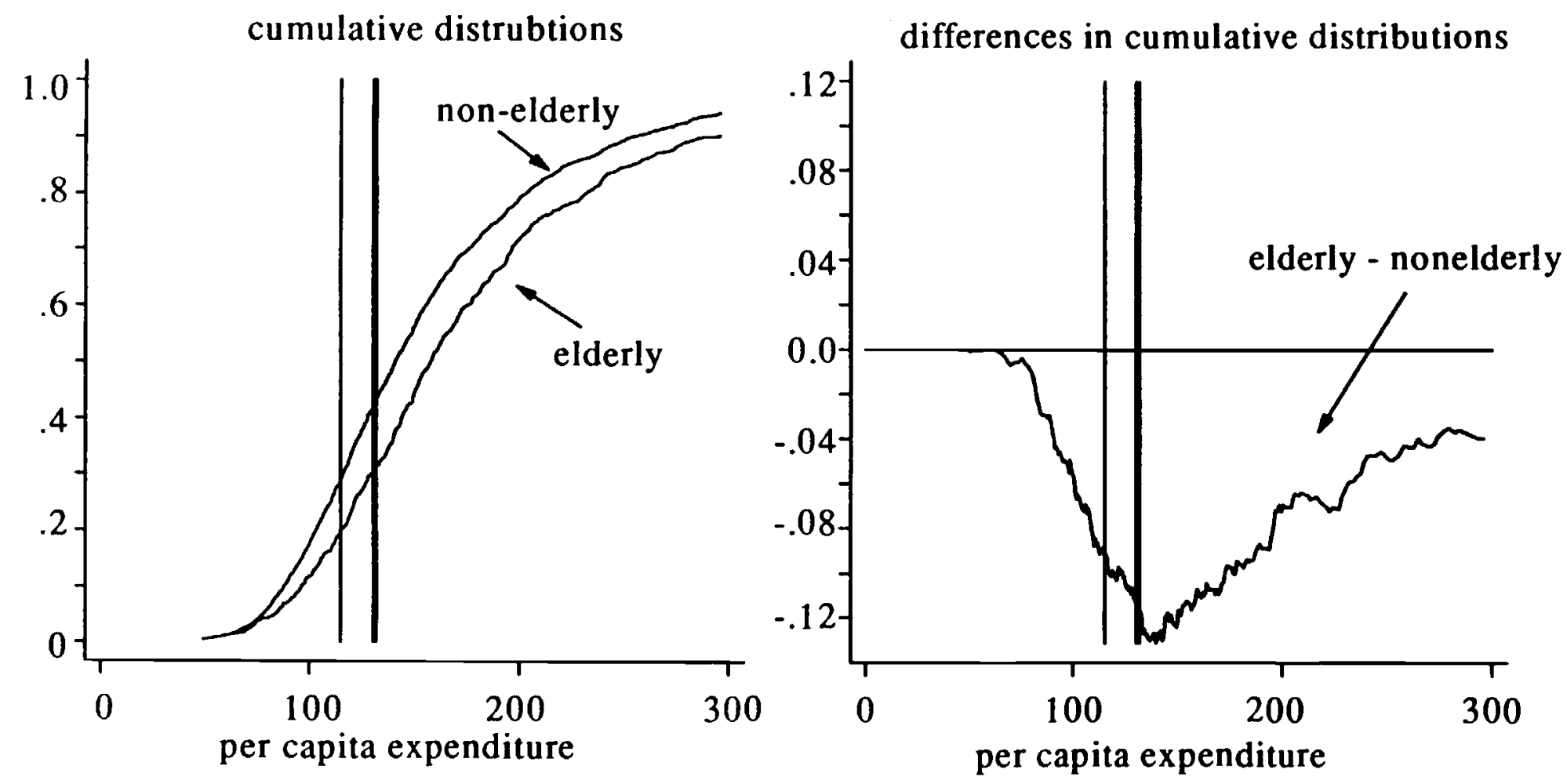

Figure 2.2: Cumulatives of per capita expenditure, rural Gujarat 


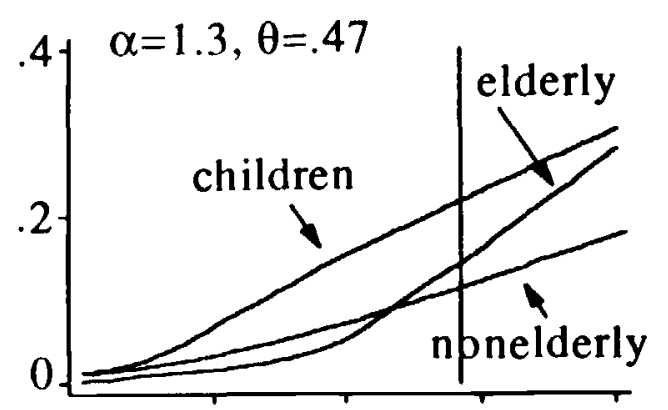

$0 \quad 5000$

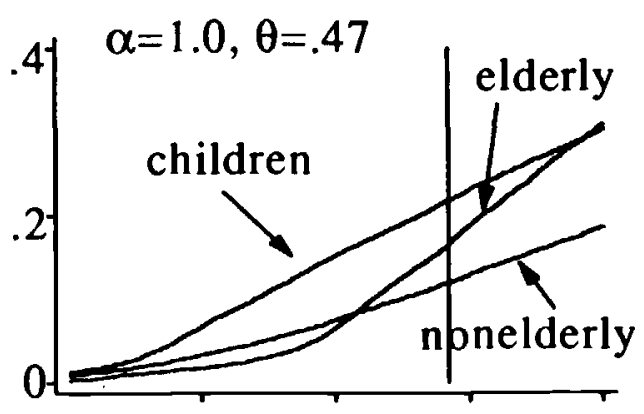

$10000 \quad 15000 \quad 20000$
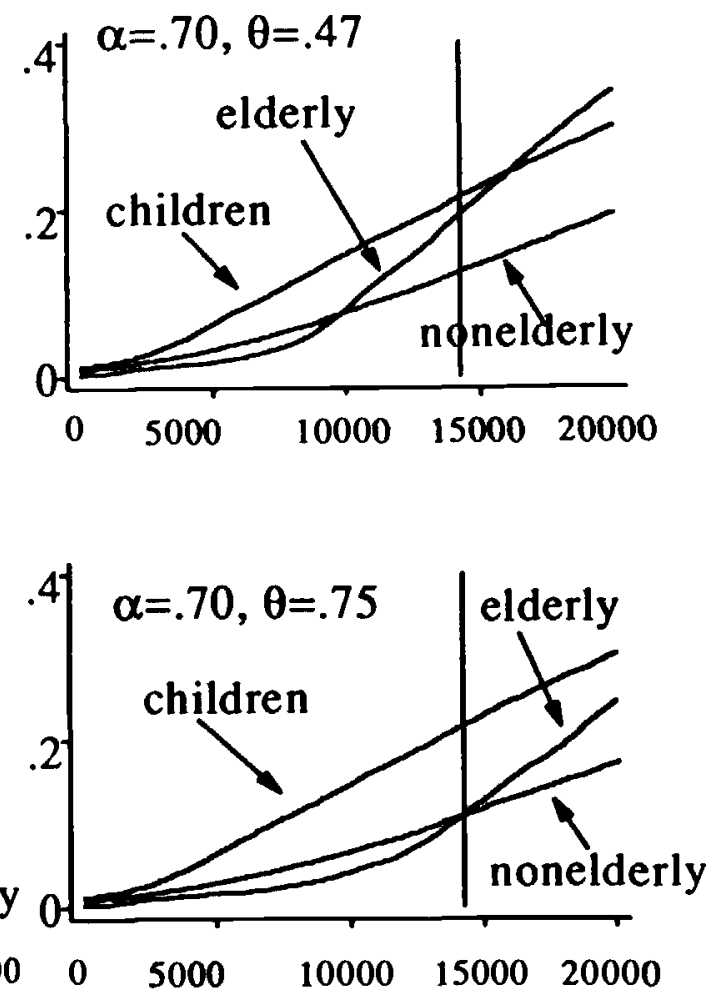

family income (2-adult 2-child base) 


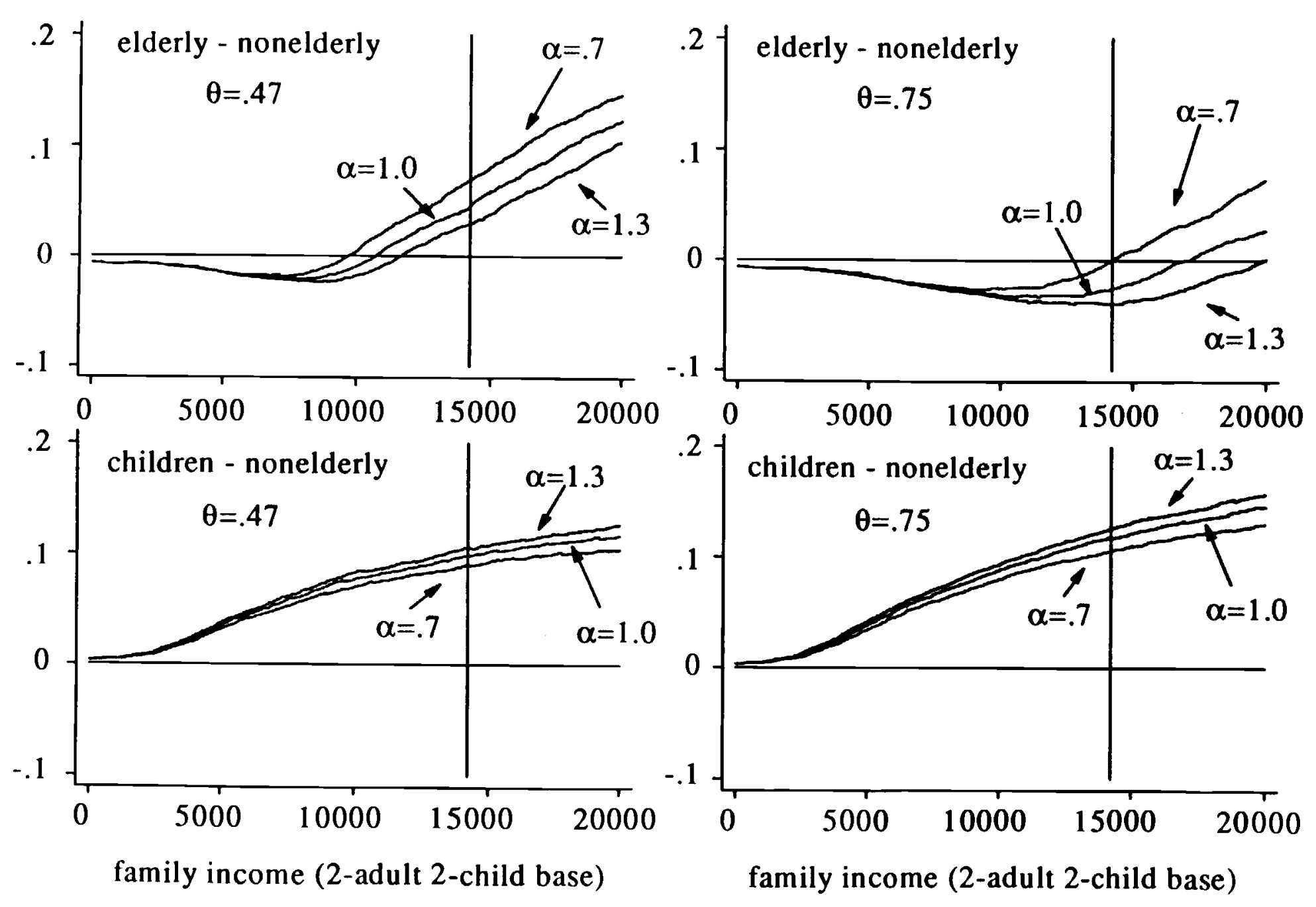

Figure 2.4: Differences in cumulatives with different assumptions about child costs and scale economies 

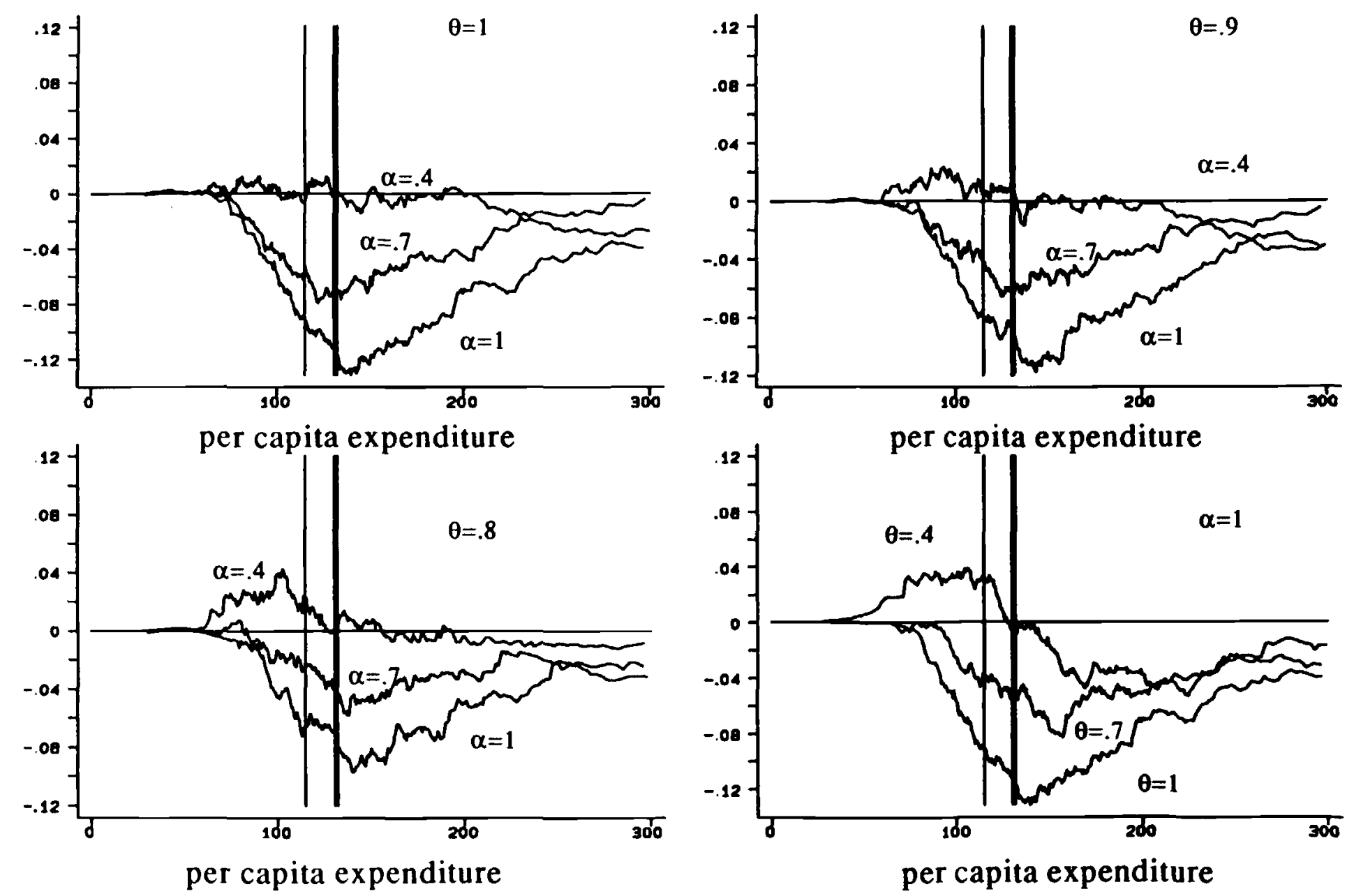

Figure 2.5: Differences in cumulatives, rural Gujarat 

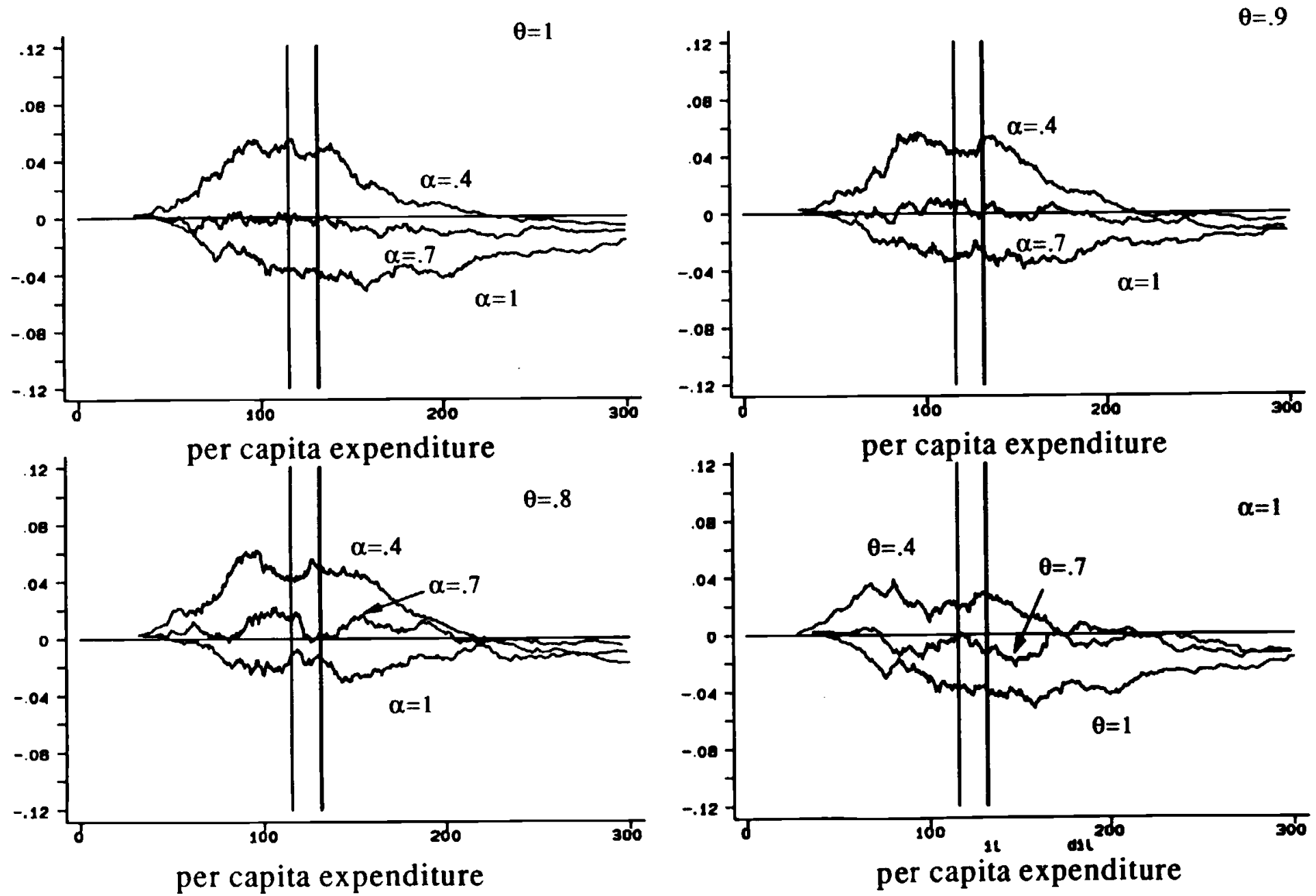

Figure 2.6: Differences in cumulatives, rural Maharastra 


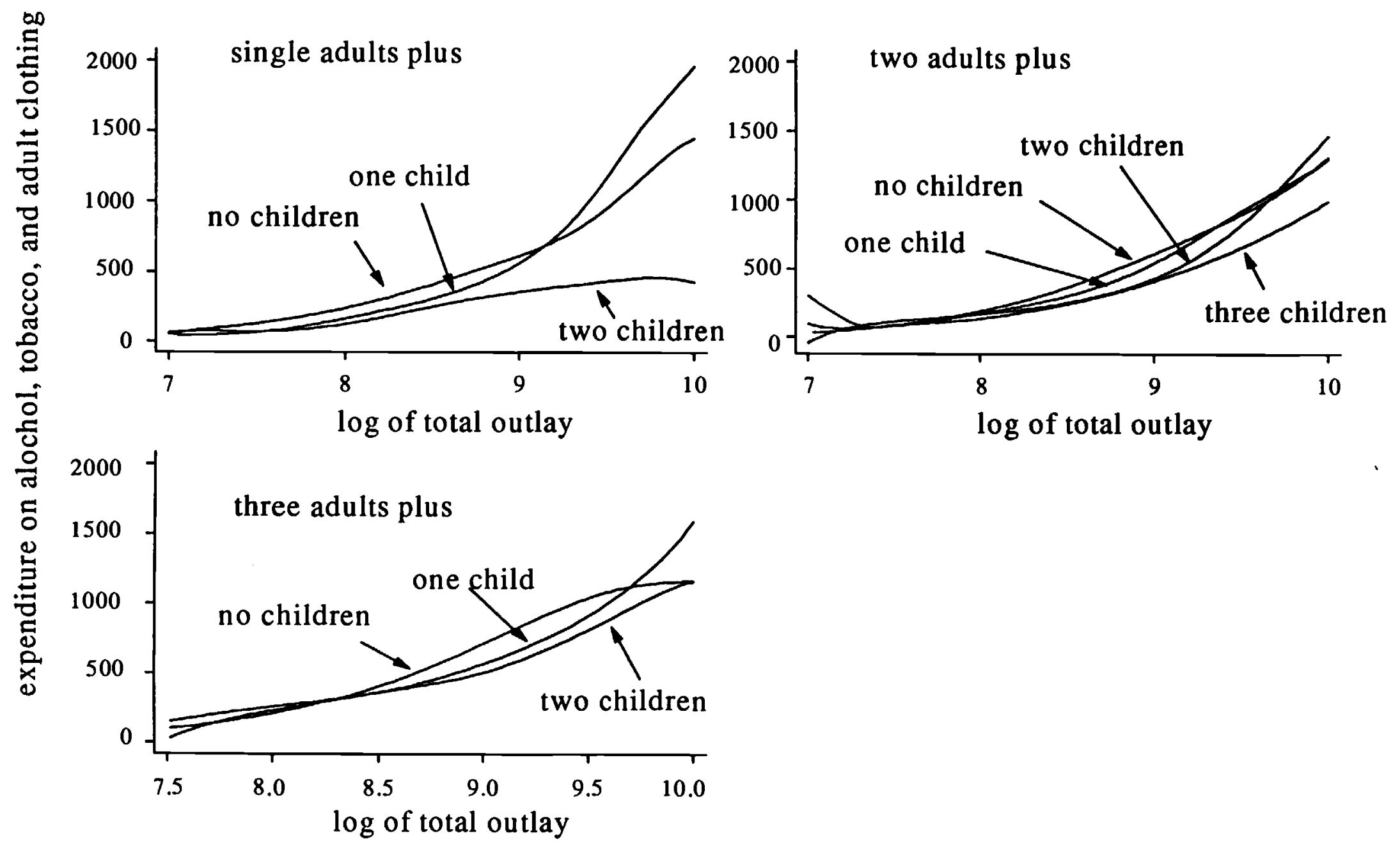

Figure 3.1: Adult good Engel curves for different family types 


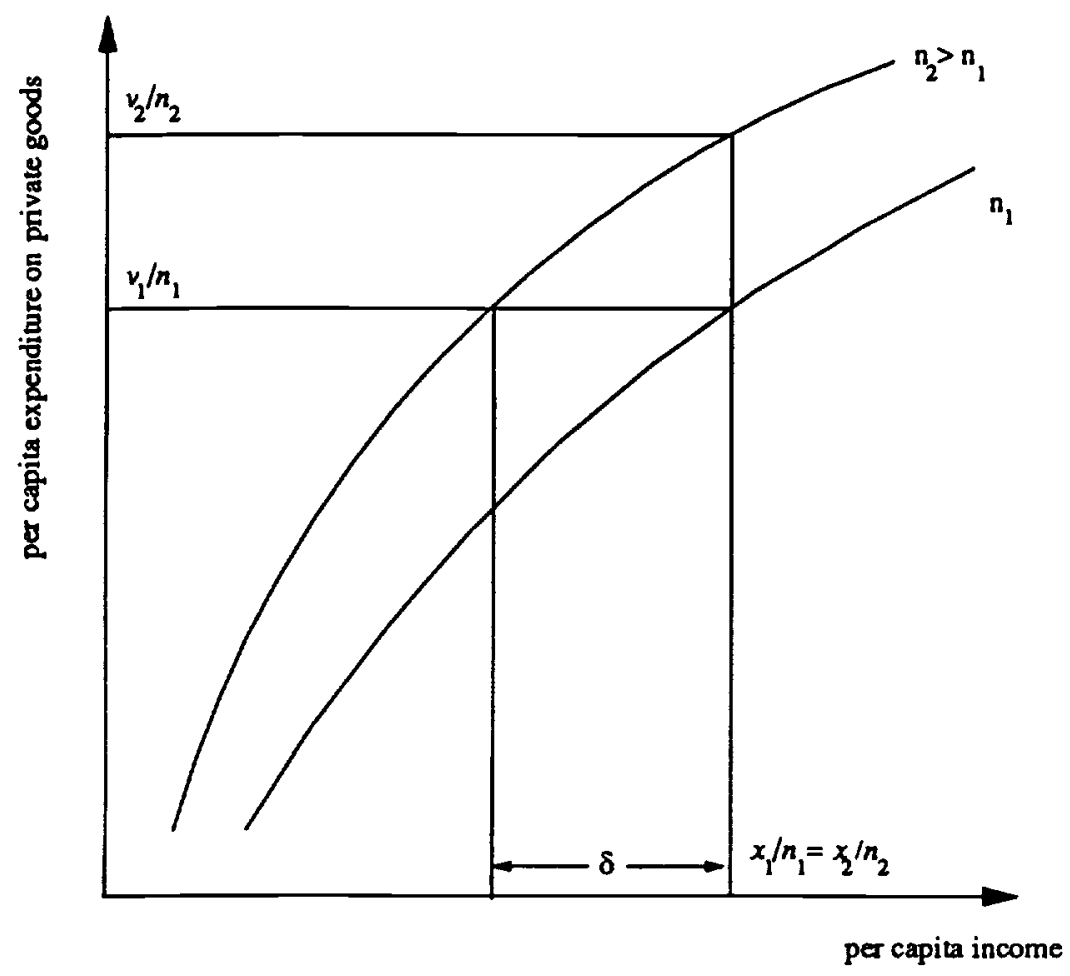

Figure 3.2: Private goods expenditure and the discount to family size 


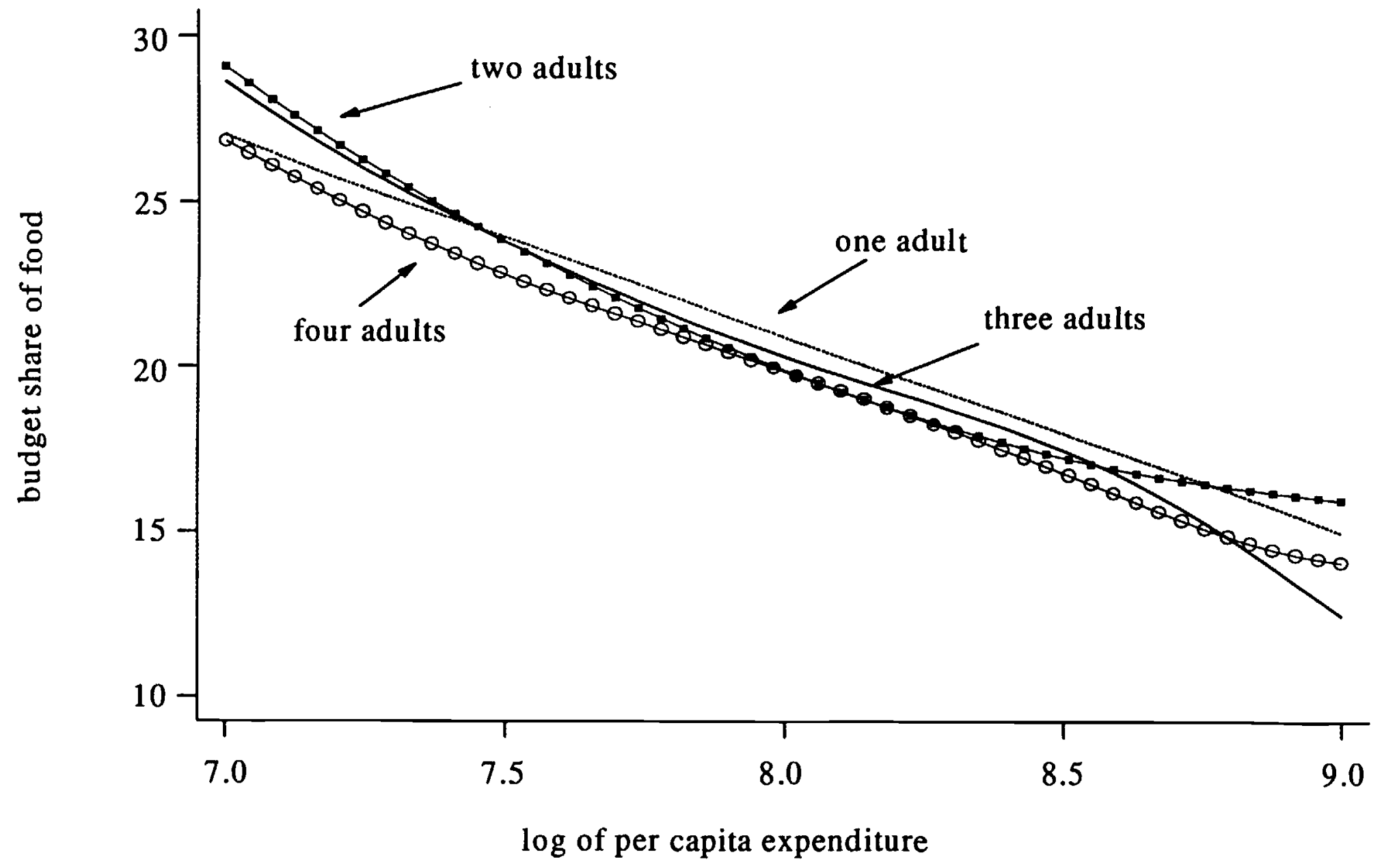

Figure 3.3: Food Engel curves for non-elderly adult households 